Ernest Orlando Lawrence

Berkeley National Laboratory

\section{$00+1 \sqrt{20}$ \\ MAY 12 POST \\ OSTI}

Energy \& Environment Division

Indoor Environment Program

1995 Annual Report

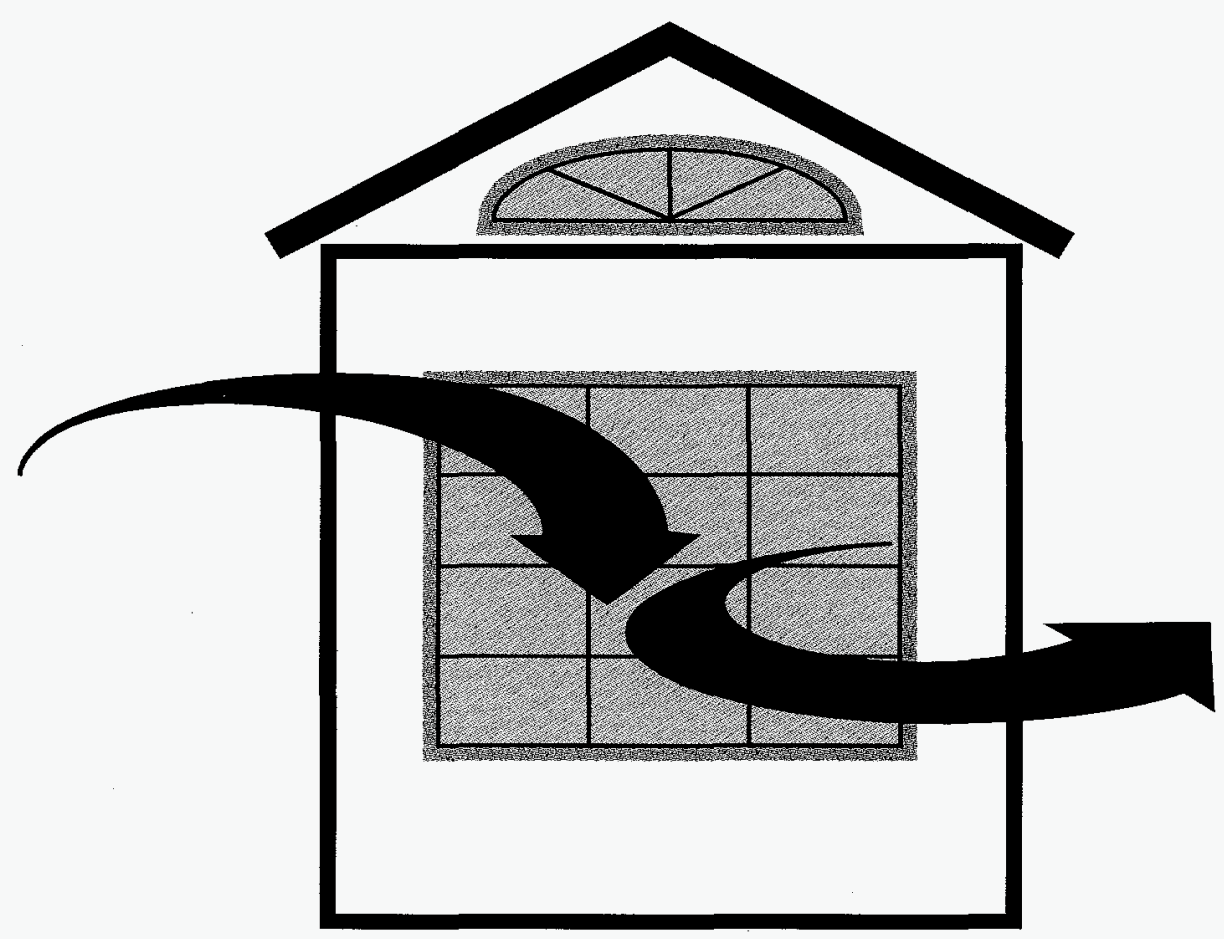

June 1996 
Available to DOE and DOE Contractors from Office of Scientific and Technical Information P.O. Box 62, Oak Ridge, TN 37831

Prices available from (615) 576-8401

Available to the public from National Technical Information Service U.S. Department of Commerce

5285 Port Royal Road, Springfield, VA 22161

Prepared for the U.S. Department of Energy under Contract No. DE-AC03-76SF00098 


\title{
Indoor Environment Program 1995 Annual Report
}

\author{
Joan M. Daisey, Program Head
}

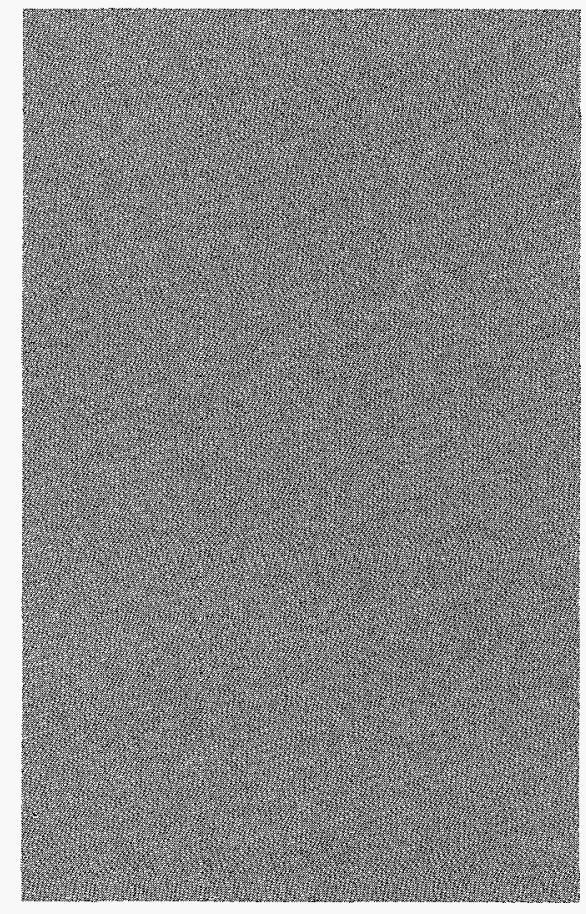

Energy \& Environment Division Ernest Orlando Lawrence Berkeley National Laboratory University of California Berkeley, California 94720

(510) 486-5001

Report No. LBL-38351

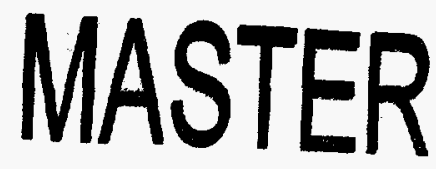




\section{DISCLAIMER}

This report was prepared as an account of work sponsored by an agency of the United States Government. Neither the United States Government nor any agency thereof, nor any of their employees, make any warranty, express or implied, or assumes any legal liability or responsibility for the accuracy, completeness, or usefulness of any information, apparatus, product, or process disclosed, or represents that its use would not infringe privately owned rights. Reference herein to any specific commercial product, process, or service by trade name, trademark, manufacturer, or otherwise does not necessarily constitute or imply its endorsement, recommendation, or favoring by the United States Government or any agency thereof. The views and opinions of authors expressed herein do not necessarily state or reflect those of the United States Government or any agency thereof. 


\section{DISCLAMMER}

Portions of this document may be illegible in electronic image products. Images are produced from the best available original document. 


\section{Contents}

\section{INTRODUCTION}

ENERGY PERFORMANCE AND VENTILATION IN BUILDINGS

Duct systems in single-family residences

Aerosol-based duct-sealing technology 3

Rooftop packaged air conditioners and ductwork in small commercial buildings

Ventilation and infiltration in high-rise apartment buildings

Thermal conditioning of commercial buildings

International studies in ventilation modeling

Residential ventilation systems

Development of smart ventilative cooling systems...

Performance evaluation of phase-change wallboard for residential cooling application ................................................... 12

Low-flow fume hood

INDOOR RADON RESEARCH

Atmospheric pressure variations as a source of radon entry into buildings.

Wind-induced ground-surface pressures around residential buildings

Developing a methodology for identifying high-radon areas of the United States

CHARACTERIZATION OF INDOOR POLLUTANTS

Development of a carbon monoxide passive sampler

Phase distributions of polycyclic aromatic compounds using the high-capacity integrated organic

gas and particle sampler

Field study of indoor air quality at a site of subsurface gasoline contamination

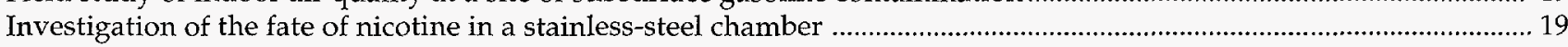

VENTILATION AND INDOOR AIR QUALITY

Evaluation of ventilation system materials as sources of volatile organic compounds in buildings ............................. 21

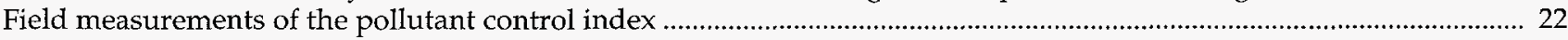

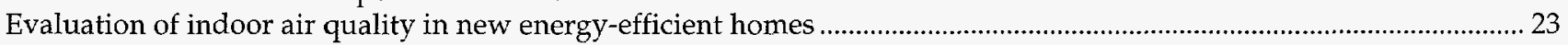

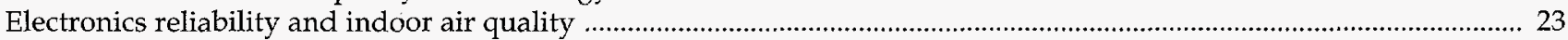

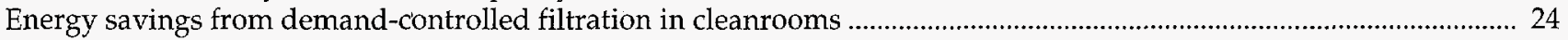

INDOOR AIR EXPOSURES AND RISKS

Development of new VOC exposure metrics related to "sick building syndrome" symptoms in office workers

Associations of measured temperatures with "sick building syndrome" symptoms in the

California Healthy Building Study

Healthy-building intervention studies ....

Statistical tools for physiologically based population pharmacokinetic modeling 


\section{Introduction}

Buildings use approximately one-third of the energy consumed in the United States. The potential energy savings derived from reduced infiltration and ventilation in buildings are substantial, since energy use associated with conditioning and distributing ventilation air is about 5.5 EJ per year. However, since ventilation is the dominant mechanism for removing pollutants from indoor sources, reduction of ventilation can have adverse effects on indoor air quality, and on the health, comfort, and productivity of building occupants.

The Indoor Environment Program in LBL's Energy and Environment Division was established in 1977 to conduct integrated research on ventilation, indoor air quality, and energy use and efficiency in buildings for the purpose of reducing energy liabilities associated with airflows into, within, and out of buildings while maintaining or improving occupant health and comfort. The Program is part of LBL's Center for Building Science. Research is conducted on building energy use and efficiency, ventilation and infiltration, and thermal distribution systems; on the nature, sources, transport, transformation, and deposition of indoor air pollutants; and on exposure and health risks associated with indoor air pollutants. Pollutants of particular interest include radon; volatile, semivolatile, and particulate organic compounds; and combustion emissions, including environmental tobacco smoke, $\mathrm{CO}$, and $\mathrm{NO}_{\mathrm{x}}$.

Research on exposure and risk analysis for indoor air pollutants provides a broad perspective on indoor air quality and the associated health and comfort risks. Such research helps establish the relative significance of various categories of pollutants. Methods for estimating distributions of exposures for populations and new exposure metrics and risk-assessment methods, based on an understanding of fundamental biological processes, are developed as part of this effort.

Studies of whole buildings are undertaken infield experiments. Relationships among human health, comfort and productivity, and environmental and building factors are investigated in such studies. Wholebuilding field studies also provide knowledge of subsystem dynamics with respect to energy and air movement. and aid in the development of representative databases for modeling U.S. buildings' energy use in as well as population exposures to indoor pollutants.

Air infiltration and ventilation rates are measured and modeled for residential and commercial buildings to understand energy transport and thermal losses from various components of building shells and ventilation systems. Methods for reducing energy losses are developed based on these studies. The effectiveness of ventilation systems for pollutant removal is also investigated. Methods for characterizing ventilation and building energy use are developed for experimental and applied uses.

Indoor air quality studies focus on understanding the dynamic processes that control pollutant sources, transport, transformation, deposition, re-emissions, and removal. Spatial and temporal variability of pollutants are also characterized. This research provides the basis for developing models for population exposures to various pollutant types.

Research on control technologies and strategies is directed toward developing the most cost-and energy-efficient method for each class of pollutant. Since source controls are often the most effective and energy-efficient method to improve indoor air quality, emissions from various types of indoor sources (combustion sources, building and furnishing materials, consumer products, office equipment, and so on) are characterized with respect to chemical composition and rates of emission. Entry of soil gases, containing radon and organic pollutants, into buildings is investigated through modeling and field measurements. The effects of ventilation and other control methods on source strengths and energy usage are investigated and evaluated.

\section{Program Staff}

Joan M. Daisey*, Program Head

Jeff Alexander ${ }^{+}$

Carmen Alverez ${ }^{\dagger}$

Cheryl Anderson ${ }^{+}$

Morten Andresen ${ }^{\ddagger}$

Michael Apte

Fred Bauman $\ddagger$

Fred Bauman $¥$

Patrick Beagan ${ }^{\dagger}$

*Group Leader

tStudent

$\ddagger$ Participating Guest

\$Deputy Group Leader

1 'Faculty Scientist
Martin Behne ${ }^{\ddagger}$

Abra Bentley ${ }^{\dagger}$

Frederic Bois

Yves Bonnefous ${ }^{\ddagger}$

Remi Carriét

Matthieu Chanfredu ${ }^{\ddagger}$

Gee-Min Chang

Elizabeth Chong

Tegan Churcher"

Joyce Cordell

Bruno DeMartinis

Margaret Demco $^{+}$

Richard Diamond

Darryl Dickerhoff
Anushka Drescher ${ }^{\dagger}$

David Faulkner

Helmut Feustel

Marc Fischer

William Fisk ${ }^{*}$

Teresa Forowicz $Z^{\ddagger}$

Jennifer Frantz ${ }^{+}$

Nathalie Furst ${ }^{+}$

Ashok Gadgil

Katherine Ann Gallagher

Karina Garbesi ${ }^{\dagger}$

Karine Guillot ${ }^{\dagger}$

Lara Gundel

Harmut Haegele

\author{
Alfred Hodgson ${ }^{\S}$ \\ Nori Hudson \\ Richard Jansky \\ Patricia Johnson \\ David Jump \\ Eduardas Kazakevicius ${ }^{\ddagger}$ \\ Hans-Georg Kula ${ }^{\ddagger}$ \\ Douglas Lane ${ }^{\ddagger}$ \\ Nicole Lark $\ddagger$ \\ Arild Larsen ${ }^{\dagger}$ \\ Victor Lee ${ }^{+}$ \\ Ken Leiserson ${ }^{\dagger}$ \\ Yanxia Li \\ Tsair-Fuh Lin ${ }^{+}$
}


Program Staff cont.

\author{
Andres Litvak $\ddagger$ \\ K.R.R. Mahanama \\ Don Maszel $^{+}$ \\ Nance Matson \\ Jan Maurer \\ Mark Mendell ${ }^{\ddagger}$ \\ Shelly Miller-Leiden ${ }^{+}$ \\ Mark Modera \\ Stefan Morgner ${ }^{\ddagger}$ \\ Yukio Nadano* \\ William Nazaroff'" \\ Matty Nematollahi \\ Eilif Nerland $^{+}$ \\ Anthony V. Nero
}

Dale Nesbitt

Oddbjoern Nilssen ${ }^{\ddagger}$

Deborah A. Nolan"

Timothy Nuzum

Jonathan Owens ${ }^{t}$

Bernd Paatsch ${ }^{\dagger}$

Doo Park $\ddagger$

Andy Peri ${ }^{\ddagger}$

Phillip Price

Richard Prill

Kenneth Revzan

William Riley ${ }^{\dagger}$

Allen Robinson ${ }^{\dagger}$

Antonie de Ruijter ${ }^{\ddagger}$
Lev Ruzer $\ddagger$

Payam Saisan ${ }^{+}$

Gail Schiller-Brager"'

Richard Sextro

Bharat Shah ${ }^{\ddagger}$

Max Sherman

Romeo Simionas ${ }^{\ddagger}$

Brian Smith

Martyn Smith

Robert Spear"'

Corina Stetiu

Carol Stoker

Holger Suess ${ }^{\ddagger}$

Eugene Suhh"
Doug Sullivan

JoAnn Ten Brinke ${ }^{\dagger}$

Tracy Thatcher

Gregory Traynor

Burke Treidler

Arnaud Van Den Bossche ${ }^{+}$

Mike Van Loy ${ }^{+}$

More Wang ${ }^{\ddagger}$

Derek Yegian ${ }^{+}$

Andrew Young ${ }^{+}$

Lan Zho ${ }^{+}$ 


\section{Energy Performance and Ventilation in Buildings}

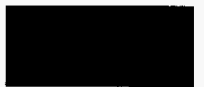

Duct Systems in Single-Family Residences

M. Modera, D. Dickerhoff, D. Jump, B. Treidler, I. Walker and D. Wang
Residential thermal distribution systems, which in the U.S. are predominantly duct systems, are a key determinant of space-conditioning energy use. A U.S. energy savings potentialstudy we performed for DOE in collaboration with Brookhaven National Laboratory estimated a current savings potential (i.e., dissemination of existing technologies and knowledge) of almost one quad/year in 2020, and a full savings potential (i.e., with an integrated research, development and dissemination effort) of somewhat more than two quads/ year in 2020. In 1990, we initiated a multiyear research program focused on understanding and improving the efficiency of residential duct systems. Co-sponsored by the California Institute for Energy Efficiency, the U.S. Environmental Protection Agency and the Department of Energy, this research program includes: 1) performance modeling, 2) field experiments, 3) technology development, and 4) codes and standards development. The overall goal of this vertically integrated research program is to help transform the marketplace for residential thermal distribution systems.

\section{Performance Modeling}

The goal of our performance modeling work is to develop and utilize the analysis tools required to evaluate the energy and comfort performance of existing and alternative thermal distribution technologies. Our performance modeling work has focused on two areas during the past year: 1) development and application of a simple technique for predicting the energy implications of thermosiphon-induced air flows through duct systems, and 2) development and application of a model for predicting the interaction between duct systems and variable-capacity HVAC equipment.

Thermosiphon-induced flows through residential duct systems occur when heat- ing or cooling equipment is not operating, and are caused by buoyancy differences between warm and cold air in ducts and houses. We have been working to predict the impact of duct insulation levels on thermosiphon air flow rates and heat transfer rates. Simulations performed for the first week in January on a wellinsulated house in Atlanta showed that for a duct system with attic supply ducts and crawlspace return ducts, the energy losses due to thermosiphon-induced flows were $16 \%$ of the total heating load for R2 ducts, $12 \%$ for R- 4 ducts, and $7 \%$ for R8 ducts.

Since earlier work has shown that the heating or cooling capacity of the equipment connected to a duct system has a significant impact on the efficiency of that system, our simulation tool was recently augmented to allow us to simulate the performance of two-speed air-conditioners. The key finding obtained from the application of the new model was that two-speed (dual-capacity) air conditioners are much more sensitive to duct system efficiency compared to single-capacity equipment. One reason is that the efficiency of the duct system is lower when the air-conditioner is operated in itslow-speed, high-efficiency mode. However, a larger issue is the fact that inefficient ducts increase theefficiency of singlespeed equipment, and decrease the efficiency of two-speed equipment. The increased load resulting from duct losses reduces cycling losses for single-capacity equipment, but increases the fraction of time that two-speed equipment is forced to operate in its high-speed, low-efficiency mode.

\section{Field Experiments}

The purposes of our field experimentation are to: 1) improve our understanding of how thermal distribution systems perform in the field, 2) validate our mod- eling techniques, and 3) develop and test diagnostic and efficiency-improvement technologies. Our recent work in this area has focused on a field study of a residential duct retrofit protocol including duct sealing and insulation retrofits.

We undertook a major field study in Sacramento, California to measure the impact of duct retrofits-both duct sealing and duct insulating. A key part of the work was to optimize a retrofit protocol that could be used in utility demand side management and other programs. Results from the 24 houses indicate that the retrofits cut overall duct leakage area approximately $68 \%$, which translated to a reduction in envelope equivalent leakage area of approximately $14 \%$. Figure 1 shows the duct distribution system from one of the houses in the study. Figure 2 shows the variation in conduction losses for three of the duct runs. Wrapping ducts and plenums with R-6insulation translated to a reduction in average flow-weighted conduction losses of $33 \%$. These experiments also confirmed the appropriateness of using duct effective leakage area (ELA) and operating pressures to estimate leakage flows for the population, but indicated significant variations between theseestimates and measured flows on a house-by-house basis. In addition, these experiments provided a confirmation of the existence of the predicted thermosiphon flows, under winter and summer conditions. The retrofits saved on average $18 \%$ of the space conditioning energy use. Finally, average duct leak sealing and duct insulation costs per house (1800 $\mathrm{ft}^{2}$ floor area on average) were $\$ 300$ and $\$ 380$, respectively. It should be emphasized that these costs are high because of the detailed protocol involved in this study. In an actual demand-side management (DSM) program, we would ex-pect that the costs would be considerably less. 
Impacts of Duct Retrofits on Heat-Pump Performance

Research efforts to improve residential heat-pump performance havetended to focus on laboratory and theoretical studies of the equipment itself, with some limited field research focused on in situ performance and installation issues. One issue that has received surprisingly little attention is the interaction between the heat pump and the duct system to which it is connected. We made field performance measurements before and after sealing and insulating the duct systems on three heat pumps. From the pre-retrofit data we found that reductions in heatpump capacity caused by low outdoor temperatures, coil frosting, or both, were accompanied by lower duct-system energy delivery efficiencies. The conduction loss reductions attributable to adding duct insulation, and thus the delivery temperature improvements, varied widely depending on the length of the particular duct section. Pre-retrofit data indicated that supply-duct conduction losses ranged from 10 to $40 \%$ of the capacity at the supply plenum. The retrofit reduced this range to 10 to $20 \%$ and improved the uniformity of heating. In addition, we found that the use of stripheat back-up decreased after the retrofits, and that heat-pumpcycling increased dramatically after retrofit, which respectively increased and decreased savings. Finally, normalized energy use for the three systems which were operated consistently pre- and post-retrofit showed an average reduction of $19 \%$ after retrofit, which corresponds to a change in overall distribution-system efficiency of $24 \%$.

\section{Technology Development}

Our technology development work this year included three research efforts: 1) development of an aerosol-based sealing system (described below), 2) development of ducts based on a novel insulation technology (air gaps bounded by

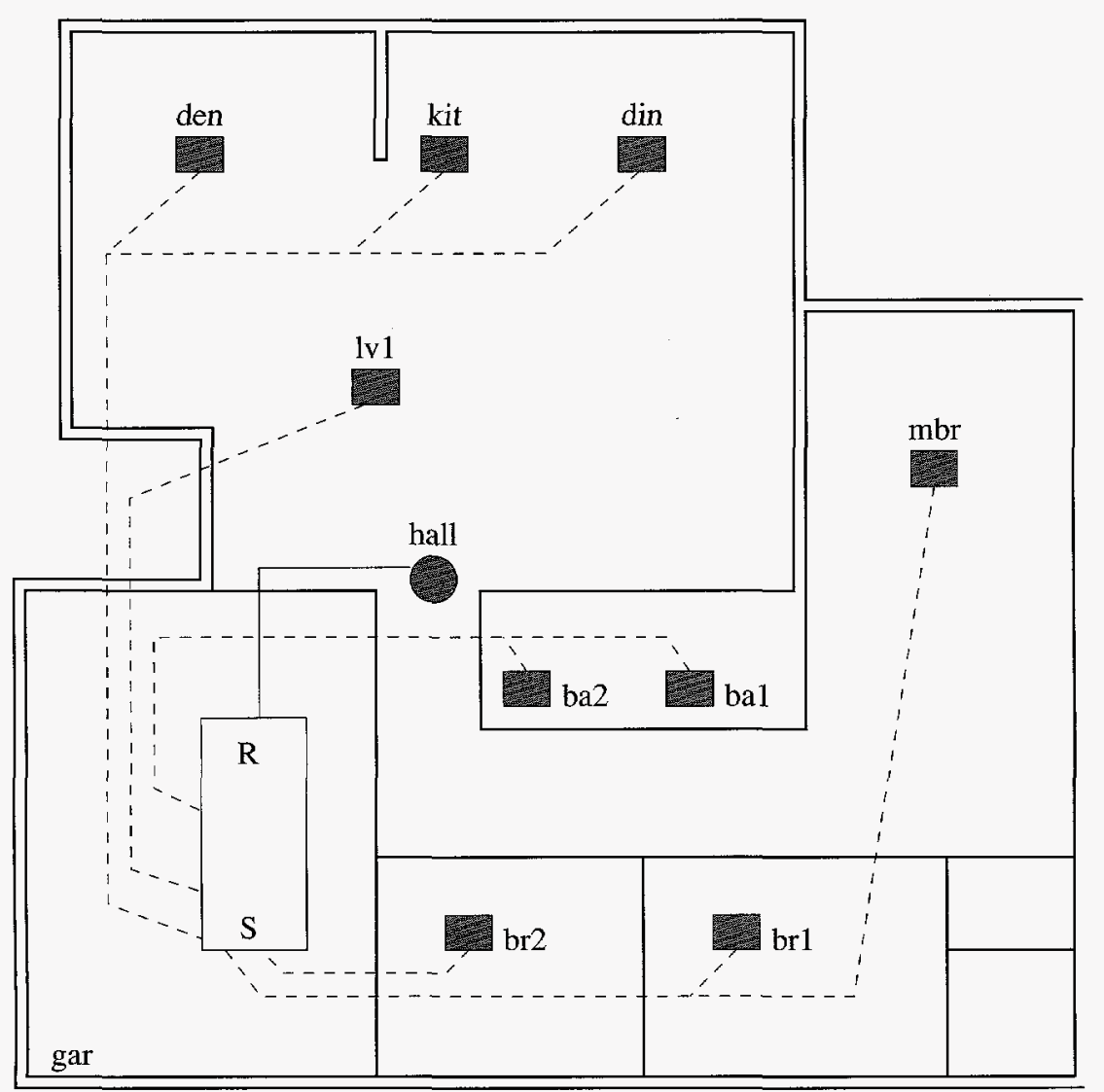

Supply register
Return register

Figure 1. Duct distribution in a typical California house.

low-emissivity plastic films), and 3) development of airtight duct fittings. The aerosol sealing technology is highlighted in a separate article within this report. The advanced insulation and airtight fittings work resulted in a technical report describing our progress on each of the technologies, as well as our assessment of the commercial feasibility of the conceptual products developed. The general conclusion of the feasibility study was that the airtight fittings are worthy of further pursuit in the short term, and that the advanced-insulation ducts may not prove to be competitive in the present market. The key issue with the advanced insulation ducts was the need to use high-cost fire-retardant plastics. The airtight fitting concept did not encounter any significant barriers, and we will continue to pursue it.

\section{Codes and Standards}

A significant barrier to improving the energy efficiency of residential duct systems is the present lack of appropriate incentives for improvement and penalties for poor performance. Our codes and standards efforts are directed toward addressing this barrier. We had two major efforts this year: 1) a sensitivity analysis of the cost-effectiveness of increasing duct insulation requirements in building codes, and 2) direction of the American Society of Heating, Refrigeration and Air Conditioning Engineers Standards Project Committee (SPC 152P) charged with developing a standardized method for determining the efficiency of residential thermal distribution systems.

The purpose of the ASHRAE standard is to develop a yardstick to compare the efficiencies of various duct systems and hydronic distribution systems on an equal footing, and thus to provide a flexible means for rewarding improved or penalizing poor performance. The standard is presently organized to provide three pathways for determining distribution-system efficiency. One pathway, geared toward researchers and measurements on oddball systems, is a direct measurement of overall system efficiency, from which distribution efficiency is derived. A second pathway, based on relatively common diagnostic measurements, is geared toward home energy rating systems and utility programs that reward improved efficiency. The third pathway does not entail any measurements, because it is directed toward houses that have not yet been built.

Tightening the requirement for duct 
insulation in building codes should reduce conduction losses from conventional duct installations to cost-effective levels. The idea is to elevate the bottom of the market by means of minimum standards that can be enforced by building inspectors. Our sensitivity analysis confirmed the expectation that typical insulation levels could be increased without incurring higher first cost to the consumer. For example, increasing the insulation level of flexible plastic supply ducts in the attic of a $1,500 \mathrm{ft}^{2}$ house from $\mathrm{R}-4$ to R-8 entails an increase in duct costs of $\$ 60$ to $\$ 100$. However, the increase in overall system capacity at design weather conditions from this insulation allows the air-conditioning equipment to be reduced, yielding a first-cost savings of $\$ 60$ to $\$ 100$. In this example the consumer receives a $\$ 30$ to $\$ 40$ annual energy cost savings without any additional first cost.

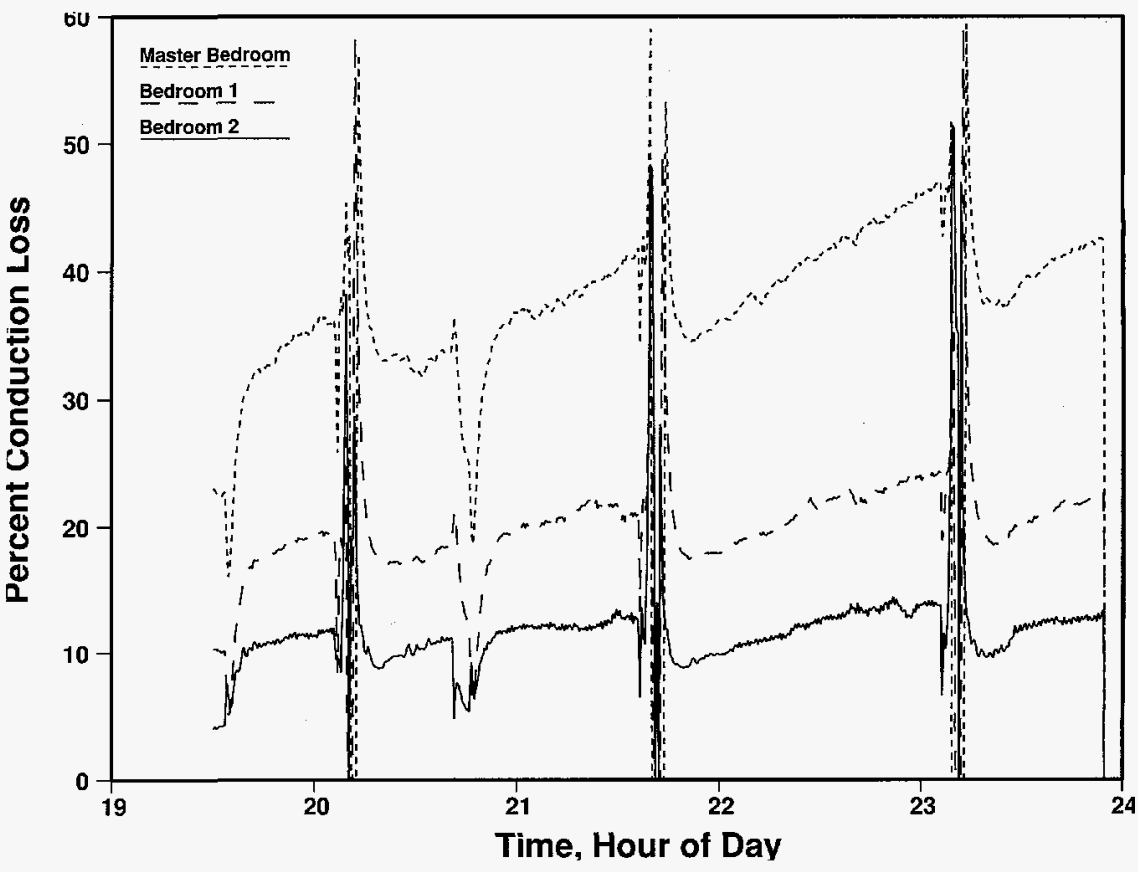

Figure 2. Results of three duct tests in a typical California house show conduction losses. Note substantially decreased system efficiency for master bedroom.

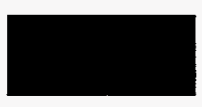

Aerosol-Based Duct-Sealing Technology

M. Modera, D. Dickerhoff, B. Smith, and D. Wang

Because the major cost associated with sealing leaks in existing air distribution systems is the labor for the location/sealing process, there is a large potential for improving the cost-effectiveness of such a retrofit by reducing the required labor. Based on field studies of duct sealing programs using HVAC contractors, labor costs vary between three and six times material costs. Moreover, field studies have found that there are many instances in which it is virtually impossible to obtain access to leaky ductwork. In the past three years we have obtained proof-ofconcept in the laboratory for a technique to seal duct systems remotely by means of an internally injected aerosol. Our laboratory tests have shown that holes in the ducts as well as leaks between duct joints can be sealed remotely, and that the sealing can be accomplished even past bends and junctions in the ductwork.

\section{Aerosol Sealing}

To develop a successful technology for remotely sealing leaks with an aerosol, the fundamental problems that we needed to solve were: 1 ) how to deposit aerosol particles preferentially at theleaks to be sealed rather than on the walls of the duct, and 2) how to have the particles span and ultimately completely seal the leaks. The solution to the first problem involved two steps: 1) choosing an aerosol that is small enough to reach the leaks before settling out of the flow stream, and large enough to leave the air-flow streamlines at the leaks, and 2) choosing/controlling the flow rate and pressure in the duct system so as to expand the range of acceptable aerosol sizes. The solution was to use turbulent flow to minimize particle transit time through the duct system to gravitational settling, and to use particles of 2 to $20 \mathrm{~mm}$ in diameter. The problem of spanning the leaks was solved by assuring that the particles were essentially solid phase, and therefore would not deform significantly when they were deposited at the leak boundaries. This was accomplished by controlling the flow rate and relative humidity of the pressurizing air stream in order to assure that all of the carrier liquid was evaporated within a short distance of the aerosol injection point.

To help us understand and predict the efficiency of the sealing process, we developed a simplified model of the rate of particle deposition on the leak boundaries. This model predicts the fraction of aerosol passing through the leak that will be deposited on the boundaries of the leak as a function of the particle size, the pressure and flow conditions, the size of the leak, and the thickness of the leak boundaries. This model was verified by videotaping the sealing process, and was shown to work remarkably well over the range of our experiments.

\section{In situ Sealing Apparatus}

Twogenerations of in situ aerosol sealing devices were designed, built and fieldtested this year. The first apparatus was designed for portability and ease of use and the second device was designed to reduce first cost and noise. The current prototype is shown (Figure). Besides performing the sealing process, the current model also measures the leakage of the duct system before, during and after sealing, thereby eliminating the need for additional hardware. The in situ sealing devices were field-tested in 75 houses this year and performed very well.

The first model was field tested by Florida Power and Light in 47 houses. This field test indicated that the sealing process took less than half the time that would have been required for conventional sealing methods, and resulted in documented leakage reductions greater than $85 \%$. In the last twenty houses treated, one technician completed the work at an average time per house of less than five 
hours. As the aerosol injection typically only takes 1 to 1.5 hours, we have been working to reduce the set-up and takedown time. We have developed new devices and methods for sealing the registers and tested them in field studies in Indiana, Pennsylvania, New Jersey, and Oklahoma.

Because the aerosol sealant material is directed to the leaks being sealed, less than $\$ 15$ in material is needed for sealing a typical duct system. The cost for tape to temporarily seal the registers during the sealing process actually was higher than the cost for sealing material, in most cases. The field tests included testing of particle and VOC concentrations before and after sealing. Total suspended particles were found to decrease after the sealing process, and no change in VOC concentrations was detected after the sealing process. The longevity of the seals is being explored by tracking the duct-system airtightness and by accelerated testing in the laboratory.
Our current work includes efforts to characterize the aerosol creation process, continued testing of seal longevity, and continued field testing by practitioners. In the coming year, we will build ten prototype systems for use by practitioners.

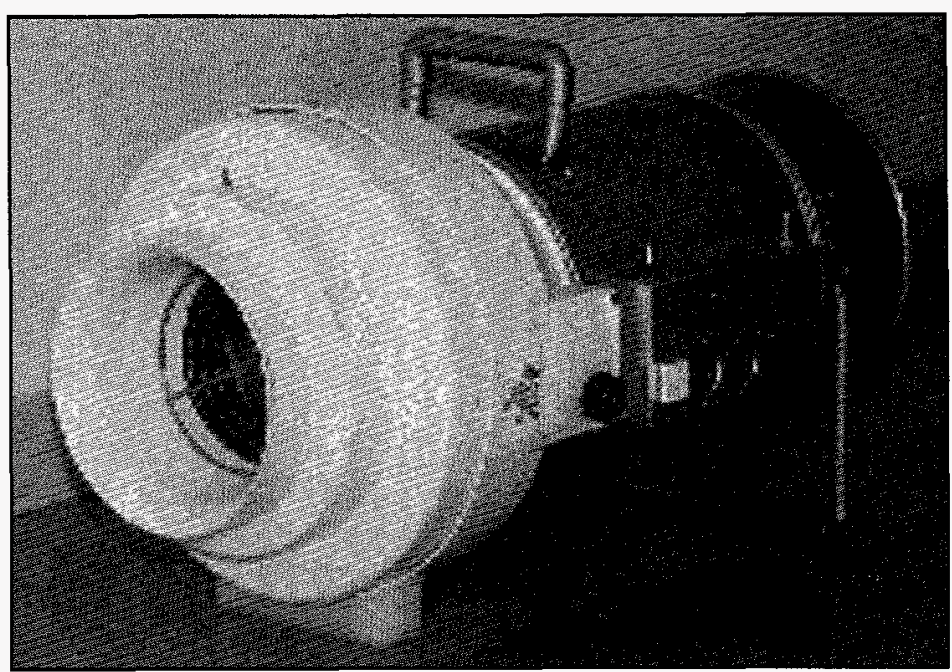

Figure. Second prototype of device that uses aerosol to seal leaky ducts in situ. The technique requires less than one hour to seal more than $80 \%$ of leakage area.

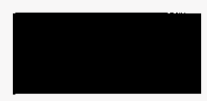

Rooftop Packaged Air Conditioners and Ductwork in Small Commercial Buildings M. Modera, W. Delp, and R. Jansky

As part of our research in improving the energy efficiency of small commercial buildings we examined relatively new five-ton packaged rooftop air-conditioner/furnaces in two strip-mall retail stores, as well as a rooftop duct sys-

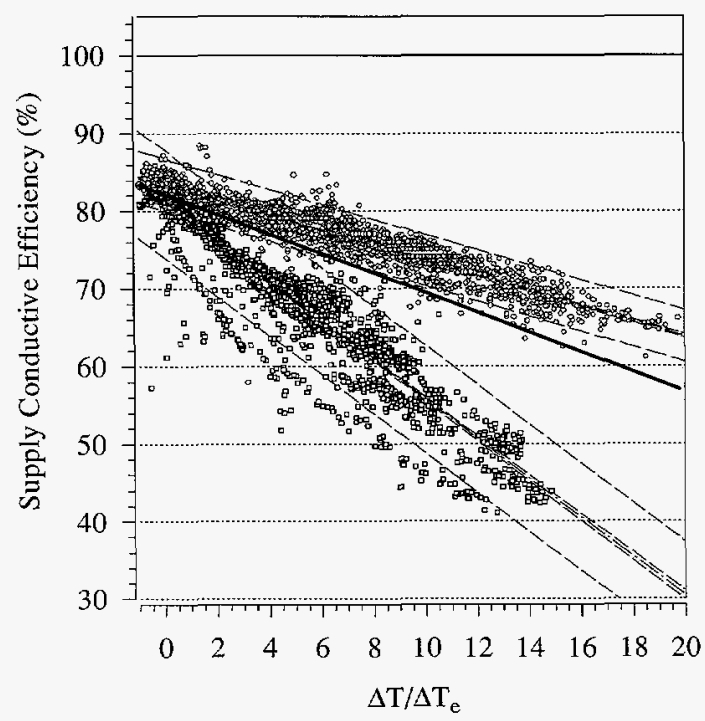

\section{- Pre-Retrofit \\ - Post-Retrofit}

Predicted change due to added insulation alone

Figure. Plot shows improved conductive efficiency of ducts in a college lecturehall in Sacramento, California, after reflectively coated insulation was added to ductwork. $\Delta T / \Delta T_{e}=$ combined weather and space load factor; $\Delta T=$ supply air temperature minus surface temperature; $\Delta T_{e}=$ temperature of supply plenum minus temperature of return plenum. the fan, flows through all diffusers and registers, building-envelope leakage, fan power and compressor power, duct and plenum pressures during normal operation, and distribution-system temperatures of all diffusers and plenums during normal cyclic operation.

For all three systems, a large fraction of duct and equipment leakage was to the outside. Average leakage area to the outside was found to be $225 \mathrm{~cm}^{2}$. Assuming outside temperature of $35^{\circ} \mathrm{C}$, supply plenum temperature of $10^{\circ} \mathrm{C}$, and room temperature of $25^{\circ} \mathrm{C}$, these leakage levels and an average pressure differential of $60 \mathrm{~Pa}$ translate to a thermal energy loss of 3 to $7.5 \mathrm{~kW}$, depending on whether the leaks are on the return or supply side of the fan. For the five-ton units studied, these losses should result in an increase in system on-time of 17 to $43 \%$ under assumed temperature conditions.

A surprising result of these case studies was that the building envelopes were significantly less tight than residential envelopes: 10 to $12 \mathrm{~cm}^{2}$ of ELA (effective leakage area) per square meter of floor area versus $6 \mathrm{~cm}^{2} / \mathrm{m}^{2}$ for pre- 1980 California houses. Visual inspection of the buildings showed that little care had been taken to keep the envelopes tight.

Because 35 to $65 \%$ of the ducts were 
located outside the conditioned space for the three systems, we measured conduction losses from these ducts and observed surface temperatures as high as $65^{\circ} \mathrm{C}$ on the sunlit surfaces of the ducts, whereas the roof-side surfaces were $35^{\circ} \mathrm{C}$ and the outdoor temperature, $33^{\circ} \mathrm{C}$.

We investigated a similar thermal/ solar problem with rooftop ductwork for a college lecture hall in Sacramento, California. In this case we found that only $60 \%$ of the energy removed by the cooling coil was reaching the conditioned space. We found that by adding one inch of insulation with a high reflective coating to the ductwork increased the delivery efficiency to $75 \%$ (Figure). Because the bottom of the ductwork was neither insu- lated nor coated by this retrofit, we found that the $\sim 15 \%$ leakage in the ductwork was not reduced by the retrofit. In addition, the improvement in delivery efficiency includes the extra heat gain on the bottom surface of the duct caused by increased solar reflection from the high reflectivity of the roof coating.
Ventilation and Infiltration in High-Rise Apartment Buildings

R. Diamond, D.Dickerhoff, and H. Feustel

Airflow in high-rise apartment buildings has been the subject of research for the past three decades. Since early work by Shaw and colleagues in the early 1970s, researchers have tried to understand the driving forces of airflow in order to recommend energy efficiency measures that do not jeopardize the health and comfort of building occupants.

Our work in this area has focused on diagnostic measurements of both air leakage and air infiltration as well as simulations of airflows throughout the building. The partners in this project include the U.S. DOE Boston Support Office, the Boston Edison Company, the Chelsea Housing Authority, and technical support was provided by the Citizens Conservation Company and two national laboratories - Oak RidgeNational Laboratory and LBNL. The demonstration site is the Margolis Apartments, a 150-unit high-rise apartment building for the elderly and handicapped, located in Chelsea, Massachusetts, in the greater Boston metropolitan area.

To better understand the air flow patterns within the high-rise building, we made air leakage measurements at the site and used the data in the multizone air flow simulation model, COMIS (Conjunction of Multizone Infiltration Specialists). We performed parametric studies taking into consideration infiltration, mechanical ventilation, windspeed, wind direction and temperature difference between inside and outside, as well as leakage distribution.

The simulation results show a strong tendency toward cross ventilation when high winds blow perpendicular to the facades (as often occurs during the winter). Furthermore, the three shafts (two staircases and one elevator shaft) introduce a significant stack effect when temperature differences between inside and outside exist. This effect is magnified by staircase heating during the winter.

The results show that the mechanical ventilation systems cannot avoid cross ventilation or reduce the stack effect significantly. Local exhaust, however, keeps units at a lower pressure than ambient, thus increasing the overall infiltration in the building. Ventilation air supplied to the corridors cannot reduce the cross flow; however, it mixes with the air coming from the windward-side apartments and therefore reduces pollutant concen- trations in the air flowing into the leeward-side apartments on the same story (Figure).

Currently, we are continuing our investigation of ventilation retrofits in high rise multifamily buildings in other parts of the country, looking in particular at how to improve the performance of the mechanical ventilation systems. In addition to developing improved diagnostic techniques, we hope to provide guidelines both for new construction and for retrofit of existing buildings.

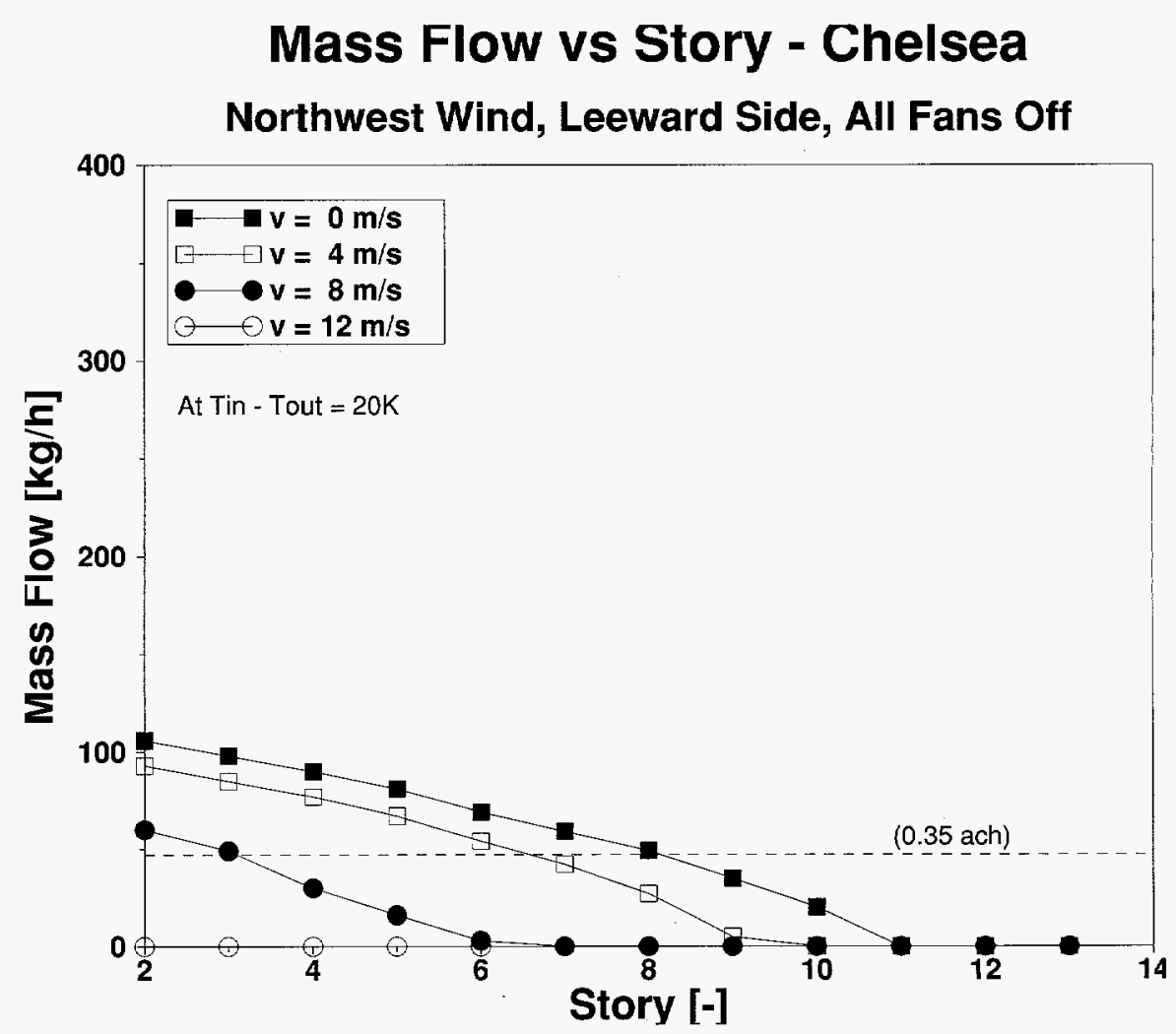

Figure. Plot compares predicted airflow as a function of story in a 150-unit high-rise apartment building in Chelsea, Massachusetts, at different windspeeds. 


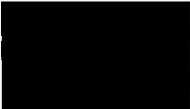

\section{Thermal Conditioning of Commercial Buildings}

H.E. Feustel, M. Behne, T. Forowicz, H. Hägele, H.-G. Kula, S. Morgner, Y. Nakano, R. Simionas, C. Stetiu, and H. Suess

Introduction

The thermal conditioning of commercial buildings' study consists of two different elements:

1) Study of hydronic radiant cooling potential

2) Environmental Assessment of LowEnergy Cooling

\section{Hydronic Radiant Cooling}

Thermal energy-distribution systems represent the vital link between heating and cooling equipment and conditioned building spaces. In the United States, approximately 6 EJ of primary energy annually pass through generally inefficient thermal distribution systems in commercial buildings. Fans that transport cool air through ductwork for cooling nonresidential buildings with all-air systems contribute a significant share to the energy use of a building. This energy consumption can be lowered by reducing the cooling load of the building, reducing the requirements of mechanical cooling, reducing the amount of air flow distributed throughout the building, and improving thermal distribution within the building.

If ventilation and thermal conditioning are separated (air-and-water systems), the amount of air transported through buildings can be reduced significantly. In this case, the cooling would be provided either by convection (e.g., fan coils) or by radiation and convection (e.g., cooled ceilings). Water is used as the transport medium, and the ventilation is provided by outside air systems without recirculating the air. Thanks to the physical properties of water, hydronic thermal distribution systems can remove a given amount of thermal energy using less than $5 \%$ of the fan energy otherwise necessary.

When compared with conventional allair systems, hydronic radiant cooling systems show several advantages. Owing to the large surfaces available for the heat exchange, the coolant temperature is only marginally lower than the room temperature, allowing the use of either heat pumps with high coefficient-of-performance values or alternative cooling sources. The reduced air supply not only lowers the fan power requirement but reduces noise and draft, thus enhancing human comfort. Combined with a displacement ventilation system, hydronic radiant cooling can achieve an even temperature distribution in the space. Reduced convective heat transfer improves the level of thermal comfort for the occupants.

The power-reduction potential of hydronic radiant cooling systems for dry climates is on the order of $45 \%$ compared to conventional all-air systems. If alternative cooling sources are applied, the savings potential increases significantly. Unfortunately, the savings potential is reduced for climates with a large portion of latent loads. In order to evaluate the moisture levels in a space cooled by a hydronic radiant cooling system, a routine was created that introduces the thermal results of RADCOOL into a moisture model. The moisture model simulates the moisture balance in the space by taking into account the influences of ventilation, infiltration, occupancy patterns and humidity sorption on the room surfaces. With this tool, a numerical study is being performed applying the technology to several climates in the U.S.

Environmental Assessment of Low-Energy Cooling for Commercial Buildings

Low-energy cooling systems are alternatives to motor-driven compressor cooling systems. Replacing motor-driven compressors constitutes a significant energy conservation measure with peak-power reduction potential.

Low-energy cooling systems provide air quality and thermal comfort to building occupants at a lower primary energy input. Before applying low-energy cooling technologies, the following steps should be taken:

- The building envelope must separate the conditioned space from the ambient influences by means of high thermal insulation and blockage of irradiation;

- internal loads must be reduced by improving the lighting efficiency and by using efficient equipment (plug-load);

- thermal storage must be implemented to reduce the amplitude and phaseshift loads into unoccupied hours;

- thebuilding's thermal distribution system must be optimized by separating the tasks of ventilation and thermal conditioning; and

- the equipment used to transport air and water through the building, as well as electric motors, must be designed to operate at high efficiency.

Only after these steps have been taken can low-energy cooling sources effectively perform their task as an alternative to compressor-driven cooling.

We see that low-energy cooling is a result of a combination of architectural design, the selection of materials, equipment, HVAC technology, and the cooling source. However, the general concern is not only the "energy" itself but also its environmental impact. This project is a co-operation with colleagues from the Eidgenössische Technische Hochschule Zürich (ETHZ), and Intep AG. Intep generated the base-case building for this study, LBNL is performing the energy calculations, and ETHZ will perform the environmental impact study.

For well-built non-residential buildings set in severaql European and NorthAmerican climates we are investigating a number of thermal distribution systems, cooling technologies, cooling sources, and energy sources for heat-operated machines:

- all-air systems vs. air-and-water systems;

- radiant cooling vs. convective cooling (air and water);

- ground coupling (air and water);

- evaporative cooling (direct, indirect, and cooling towers);

- absorption chillers (gas- and wasteheat-operated water-fired units);

- desiccant cooling (air cooling and dehumidification);

- night ventilation (direct and indirect)

- solar collectors; and

- fuel cells.

These alternative systems will be compared with a well-designed conventional reference cooling system (VAV) to make an integral assessment of both cost and environmental effects such as the greenhouse effect, ozone depletion, photo chemical smog, and acidification.

\section{Peak Power-Reduction Potential of Solar- Assisted Absorption Chillers}

The alternative cooling source investigated is a combination of absorption chillers and solar collectors. Both components have undergone significant improvements in the last few years.

Absorption chillers are heat-operated machines that use an absorbent and a gaseous refrigerant that has been vaporized in the evaporator. The evaporation 
process absorbs heat, providing the needed refrigeration. The absorption cycle uses a heat-generated operator, a heatrejecting absorber, and a liquid solution pump to produce the pressure differential necessary for the refrigeration cycle. The heat applied to the generator can come from several sources including natural gas or solar devices. The absorption cycle substitutes a physio-chemical process and a pump for a purely mechanical compressor.

Theadvantage of the absorption chiller is that only the pumps (solution pump, chiller pump, and condenser pump) consume electrical energy; the main driving force is the thermal energy required for the absorption process. Because of their limited efficiency, absorption chillers are only economical if the thermal energy can be provided at a relatively high temperature level and at low cost. If the required heat cannot be provided by solar devices, this cooling system switches to gas from electrical energy.

The main advantage of solar-assisted cooling is the correlation between the solar power and the cooling load requirement of the building. While conventional flat plate collectors have a low efficiency at high operating temperatures, newly designed flat plate collectors with transparent insulation material exceed the per- formance of even expensive vacuum tube collectors.

The use of solar-assisted absorption heat pumps as a cooling source for nonresidential buildings has a significant peak-power reduction potential. The electrical energy used to operate the absorption chiller is very small compared with the electrical energy required to operate a comparable compressor (the electrical energy requirement of the solution pump is less than $1 \%$ of the unit size). The additional energy necessary to operate the solar collector loop and the increased condenser pump consumption are only marginal. Therefore, the coefficient of performance based on the electrical requirement $\left(\mathrm{COP}_{\mathrm{el}}\right)$ is much better than that of conventional compressor systems.

The goal of this project is to assess the cooling power potential of this alternative cooling source for several California climates. The results of this assessment will be compared with the cooling power requirement and the energy consumption for a base-case building equipped with compressor cooling located in the same climate zones.

\section{Low-Flow Fume Hood}

Fume hoods are enclosed workspaces, intended to capture, contain, and exhaust fumes, vapors, and particulate matter generated inside the enclosure. In labora- tory buildings, the exhaust flows of fume hoods often exceed the fresh air supply requirements for the building'soccupants set by ventilation standards. The exhaust air requirement for fume hoods provides a severe energy penalty as all air to be exhausted has to be conditioned before it is supplied to the laboratory space.

In conventional fume hoods, containment of hazards is based on a face velocity high enough to prevent the escape of airborne contaminants from the hood into the room. This face velocity usually is about $100 \mathrm{fpm}(0.5 \mathrm{~m} / \mathrm{s})$, which amounts to approximately $500 \mathrm{~cm}\left(850 \mathrm{~m}^{3} / \mathrm{h}\right)$ for a $3 \mathrm{ft}$ wide fume hood with an open sash (compared to $36 \mathrm{~m}^{3} / \mathrm{h}$ for an occupant).

In order to study the air flow pattern and the air flow requirements for a fume hood, a mockup was built with a displacement ventilation outlet, which protects the critical perimeter of the open face. By supplying a low-turbulent displacement flow directly at the open face of the hood, we were able to reduce the exhaust flow by about $50 \%$ without decreasing the effectiveness of the hood.

Additional work is needed to optimize the supply/ exhaust flow fraction of the hood, the design of the displacement ventilation outlet, and the flow patterns within the hood to minimize air exhaust without increasing the risk of spillage.

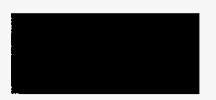

International Studies in Ventilation Modeling

H.E. Feustel and B.V. Smith

The flow of an air mass within a given building is driven by pressure differences which in turn are affected by wind, thermal buoyancy, mechanical ventilation systems or a combination of these. Airflow is also influenced by the distribution of openings in the building shell and by inner pathways.

Increased awareness of the effects of air infiltration on the overall conditioning load of buildings has led to tightened construction of building components as well as the overall building shell. Although tightness decreases infiltration rates and the related ventilation heat losses and cooling requirements, tightening has created problems with indoor air quality.

Airflow models can be divided into two main categories: single-zone and multizone models. Single-zone models assume that the structure can be described by a single, well-mixed zone. The major application is the single-story, single-family house with no internal partitions (e.g., all internal doors are open).

Nevertheless, since a large number of buildings have floor plans that would categorize them as multi-zone structures, moredetailed models taking internal partitions into account have been developed. In them, the building is described by a set of zones interconnected by flow paths. Each node represents a space (zone) with uniform pressure conditions inside or outside the building and the interconnections correspond to impediments to airflow. These network models are usually based on the conservation of mass in each of the zones in the building.

The COMIS workshop (Conjunction Of Multizone Infiltration Specialists) at LBNL led a multinational team of experts to develop a multizone airflow model on a modular basis. The group at LBNL gave special emphasis to the modular structure to facilitate the further development of the simulation tool.

\section{Annex 23}

Within the framework of a technical committee known as an annex, established by the Energy Conservation in Buildings and Community Systems program of the International Energy Agency, we are studying physical phenomena. causing air flow and pollutant transport (e.g., moisture) in multizone buildings. An important part of this annex is the comparison between model results and results from in situ tests. Before these datasets could be used for model evaluation however, internal model comparisons based on benchmark buildings were necessary.

The annex participants have undertaken a task-sharing project that spans five-and-one-half years and involves model development, data acquisition, and analytical studies. The project is structured into three subtasks:

Subtask 1: System Development A multizone airflow and pollutant-transport 
model based on the COMIS model is under development. It will incorporate flexible expert routines, additional modules, and user-friendly interfaces for input and output.

Subtask 2: Data Acquisition Datasets are being obtained and evaluated as inputs for the model.

Subtask 3: System Evaluation The model is being evaluated using intermodal comparisons as well as data obtained from Subtask 2.

The results of these subtasks are intended to help researchers and consultants and will promote energy-efficient building designs. COMIS participants intend to cooperate on state-of-the art reviews, data collection, and defining cases for evaluation with other pertinent projects. As part of its ongoing work plan, the Air Infiltration and Ventilation Centre (AIVC) will disseminate the results of this particular annex. A database for evaluation has already been prepared by AIVC.

In 1995, COMIS 2.1 was tested and distributed to interested parties. It includes a calculation of two-directional airflow through large vertical openings (e.g., open doorways) brought about by air-density differences (i.e., temperature or humidity differences in rooms connected by large openings). The User's Guide has been updated to reflect the status of the program and a Programmer's Guide has been written. Measurements have been performed to obtain data for use in the evaluation exercise. Intermodal comparisons have been performed, and the results of a first user test have been analyzed.
Thanks to its international character, COMIS is expected to become a standard in multizone airflow modeling. COMIS currently is used in Belgium, Canada, China, France, Germany, Great Britain, Greece, Hong Kong, India, Italy, Japan, The Netherlands, Sweden, Switzerland, and the United States. LBNL's Energy Performance of Buildings Group is using the model for ongoing and planned studies. In the United States, more than 20 universities, national laboratories and energy consultants are using COMTS.

Berkeley Lab is managing the annex on behalf of the U.S. Department of Energy. By the end of FY 1995, Belgium, Canada, France, Greece, Italy, Japan, The Netherlands, Switzerland, and the U.S. had officially committed to participate in the annex.

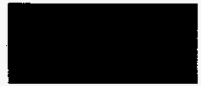

\section{Residential Ventilation Systems}

H.E. Feustel and N.E. Matson

Wehaveundertakenastudy to (1) evaluate air tightness in recently constructed single-family dwellings, (2) evaluate the effectiveness of various strategies to provide adequate ventilation, and (3) examine the use of ventilation strategies bybuilders and heating, ventilation and air-conditioning contractors. This research project focuses on single-family detached dwellings in the states of California and New York.

\section{Evaluation of Building Tightness and Ventilation Rates}

Evaluation of existing New York and California post-1980-construction homes shows that it is often necessary to provide mechanisms for supplemental ventilation when undertaking air-tightening efforts. Of the 47 New York State Energy (NYSE)Star houses, the tightest data set reviewed, only $23 \%$ of these houses met the ASHRAE Standard 62 ventilation standard while $79 \%$ of these houses met the ASHRAE Standard 119 for building tightness. The New York control houses and the California houses, having higher normalized leakage values than those of the NYSE-Star houses, were more likely to meet the ventilation standard (54\% of New York controlhouses, $50 \%$ of California houses). In many cases, however, supplemental ventilation may be needed when the houses are not able to meet the ventilation standard. Of the New York control houses, $52 \%$ were able to meet the tightness standard. The California houses all met the standard, because of the much higher allowed normalized leakage values for temperate California cli- mates.

\section{Evaluation of Residential Ventilation} Strategies

The COMIS analysis looked at the hourly performance of five different ventilation scenarios (single port fan with intake louvers or an outside air duct, multiport fan with intake louvers or an outside air duct, and a heat recovery ventilator). Two types of prototypical houses were analyzed, a one-story and a two-story houses with various foundation types (basement and crawlspace for New York climates, slab and crawlspace for California climates). The hourly performance was reviewed for the peak and lowinfiltration days (selected using the RESVENT model). The hourly average and daily average air change rates for the base case houses (nocontinuous ventilation systems) tended to be below therecommended 0.35 / $h$ for the peak and low infiltration days in the New York and California one-story houses. The New York and California twostory houses were above $0.35 / \mathrm{h}$ for both peak and low infiltration days. The heat recovery ventilator and the single and multiport systems with outside air ducts were best at increasing the air change rates to above $0.35 / \mathrm{h}$ on both peak and low infiltration days. The singleand multi-port systems with intake louvers were able to increase the air change rates to above 0.35 / $h$ on the peak infiltration days, but not always on the low infiltration days. To insureadequate ventilation, theoutsideair damper could be adjusted to a wider open setting for the outside air duct scenarios and additional wall intake louvers could be installed for the intake louver scenarios. Zone airflow analyses showed that systems with intake louvers provided higher air change rates between the bedrooms and other zones than the outsideair ductor heat recovery ventilator systems dependent on the central system for air distribution.

\section{Economic Analysis}

Additional space conditioning and fan energy consumption and the corresponding additional energy costs were related directly to the operation of ventilation systems. For the prototypical houses, gas consumption for space conditioning increased by 9 to 109 therms/year ( 2 to $34 \%$ ) depending on the climate and the type of ventilation system used. Electricity consumption for space conditioning and fans increased by 301 to $1,073 \mathrm{kWh} /$ year ( 16 to $65 \%$ ) depending on the climate and type of ventilation system used. Additional annual space conditioning and fan operating costs related to the ventilation systems ranged from $\$ 99$ to $\$ 197$, depending on the climateand type of ventilation system used. The heat-recovery ventilator had the lowest annual operating costs for all New York combinations and for all, but the Oakland, California combinations. ForOakland, the energy-efficient, single-port fan had the lowest operating costs. Lifecycle costs, however, tell a different story. Because there was only a small differential between annual operating costs for the different 
ventilation scenarios, the lifecycle costs were highly dependent on the initial installation costs for the systems. Based on Synertech's surveys of equipment installersand distributors, themultiport and heatrecovery ventilator systems had initial installation costs ranging from $\$ 1,350$ to $\$ 3,120$. The single-port scenarios had initial installation costs of less than $\$ 1,000$, ranging from $\$ 620$ to $\$ 700$. Due to the small differences in annual operating costs and significant differences in initial installation costs, the single-portenergy-efficient fan (withintakelouversoroutsideairducts) had the lowest lifecycle costs for the New York climates. For the California climates, the standard single-port fan with intake louvers had the lowest lifecycle costs, followed by the standard single-port fan with an outside air duct. The percent difference between the lowest lifecycle cost scenario and the other single port scenarios ranged from 9 to $23 \%$ while the percent difference between the lowest life cycle cost scenario and the multiport and heat recovery ventilator scenarios ranged from 6 to $256 \%$.

\section{Residential Ventilation Survey}

The surveys, conducted by Synertech for this project, showed that while builders and contractors had experience with variousventilation strategies, they had installed very few of these systems on average. The builders and contractors stated that it was relatively easy to obtain ventilation system materials and equipment. Therespondents tothe wholesaler/distributor surveystated that they had ventilation system materials and equipment on hand, but they sold the basic systems (i.e., bathroom and kitchen fans) more often than the advanced multiport and heat-recovery ventilators.

\section{Conclusion}

In conclusion, we found that there is often a need to consider supplemental ventilation when building a tight house. Our analysis of ventilation strategies showed that, when sized correctly for both lowand peak-infiltration days, the ventilation strategiesstudied were effective in providing sufficient ventilation. Finally, contractors and builders were aware of ventilation equipment. However, they werelikely to be more familiar with the basic ventilation equipment than with the advanced whole house systems.

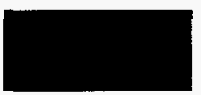

\section{Development of Smart Ventilative Cooling Systems}

H.E. Feustel and H. Suess

Ventilation has been identified as a prime candidate to replace compressor cooling in some climates. Ventilative cooling is any strategy that utilizes outdoor air in the cooling process, whether by direct cooling ventilation, in which ventilation air is supplied as cooling is desired, or by thermal storage ventilation, in which ventilation air is supplied primarily during off-peak hours to reduce the temperature of the thermal mass in a building. Direct cooling ventilation works by removing internal heat gains. The cooling effects of direct ventilation are enhanced because people feel cooler when air moves over them. Direct ventilation is used primarily in the transition climates, that is, those that are not extreme (outdoor temperatures below $32^{\circ} \mathrm{C}$ ) with small (less than $10 \mathrm{~K}$ ) diurnal temperature swings. For example, such a system appears to work well in Hawaii.

Thermal storage ventilation only works in climates with large diurnal temperature swings. Air is supplied to the building during cool periods, both cooling the indoor air and storing coolness in the structure. Ventilation is reduced when the outdoor temperature rises. The indoor temperature rises more slowly than the outdoor temperature because the cool structure absorbs heat from the indoor air. Thermal energy storage is a means of accommodating the delay between the availability of cooling resources and the need for building cooling load.

Both methods of ventilative cooling may be either natural or induced. Induced ventilation must be used when the natural driving forces are inadequate or when the large openings in the building envelope that are required for natural ventilation would create an unacceptable security problem.

Control of many of the alternative systems is inherently more complex than compressor cooling. A "smart control strategy" for a single-zone building has been developed within the framework of the multiyear, multidisciplinary "Alternatives to the Compressor Cooling for Residences" project. The control strategy begins with a determination of the need for cooling, based on whether the operative temperature is above the upper summer comfort limit the uniform temperature of a radiantly black enclosure in which an occupant would exchange the same amount of heat by radiation plus convection as in the actual non-uniform environment. Control measures include evaporative cooling, ventilative cooling, and ceiling fan operation. Evaporative cooling is invoked by override or when the operative temperature is above $27.5^{\circ} \mathrm{C}$. If neither of the conditions is met, ventilative cooling is used when theinterior/exterior temperature difference is greater than $2 \mathrm{~K}$, and ceiling fans are turned on otherwise. If the operative temperature is between 20 and $26^{\circ} \mathrm{C}$ and at least $2 \mathrm{~K}$ higher than the outdoor temperature, precooling might be used in the form of ventilation.

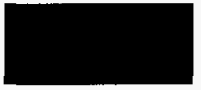

Performance Evaluation of Phase-Change Wallboard for Residential Cooling Application H.E. Feustel and C. Stetiu

Cooling of residential California buildings contributes significantly to electrical consumption and peak demand. The peak cooling load requires utilities to build, operateand maintain peak-power plants, and size their distributionnetwork accordingly. For the building owner, the peak-cooling load determines the size of the equipment and the choice of the cooling source.

Large thermal storage devices have been used in the past to overcome the shortcomings of alternative cooling sources, or to avoid high demand charges. Buildings designed to make use of thermal storage include features which increase thermal mass. These may be used for storage only, or may serve both as storage and as structural elements. Several structural materials satisfy the requirements for sensible heat storage; these include concrete, steel, adobe, stone and bricks.

Latent heat storage usesa phase-change material as a storage medium. This concept is particularly interesting for light- 
weight building construction. While undergoing phase-change freezing, melting, condensing, and boiling a material absorbs or releases large amounts of heat with little change in its temperature (E-Source, 1993). Phasechangeapplications typically involve liquid/solid transitions. The phase-change material is solidified when cooling resources are available, and melted when cooling is needed. PCMs have two important advantages as storage media: they can offer an order-of-magnitude increase in heat capacity, and their discharge is often almost isothermal (Feustel et al, 1992).

The thermalbuilding simulation model RADCOOL is being used in this study (Stetiu etal, 1995). To test the program with dynamic physical properties, we modeled a living room with $35 \mathrm{~m}^{2}$ floor area and two exterior walls. The window area is $20 \%$ of the exterior wall area. All walls and the ceiling are covered with PCM-treated wallboard containing $20 \%$ paraffin with a melting temperature of $25^{\circ} \mathrm{C}$ and a melting range

of $\mathrm{t}=\mathbf{4} \mathrm{K}$. The interior walls are stud walls covered with $0.015-\mathrm{m}$ treated gypsum board on both sides.

During the time of occupancy (6:00 through 22:00 hours) there is a constant load of $550 \mathrm{~W}$ (four occupants and a television set), and $100 \mathrm{~W}$ of electric lights during the last two hours of the occupied period. The thermal storage is discharged by means of ventilation. Ten air changes per hour $(\mathrm{ACH})$ of outside air provide ventilative cooling if the ambient air is below $25^{\circ} \mathrm{C}$. Above $25^{\circ} \mathrm{C}$, the ventilation rate is being reduced to $1.5 \mathrm{ACH}$. In case the outside air temperature is below $19^{\circ} \mathrm{C}$, outside air is mixed with recirculation air in order to keep the supply air temperature at the $19^{\circ} \mathrm{C}$ level.

The climatic conditions chosen represent one of California's transition climates, where cooling of residential buildings is only necessary for a few days during the year. Theseclimates contributesignificantly to the electrical peak demand, but produce little revenue for the utilities.

Figure 1 shows the ambient temperatureprofilefor a hot period in June. Whereas the ambient temperature profile shows a peak on the fourth day of the period, the solar radiation is surprisingly stable for the seven-day period.

The simulation results (Figure 2) show that when compared with single-conventional wallboard, doubling the thickness of the wallboard only provides minimal reduction of the peak operative temperatures. Maximum reduction values are be- low $1 \mathrm{~K}$. The use of PCM-treated wallboard provides a good temperature reduction for the first day of the heat spell, but saturation of the latent storage diminishes the reduction potential. Doubling PCMtreated wallboard shows a significant improvement in the temperature reduction potential. After two days of reducing the operative temperature by more than $4 \mathrm{~K}$, on the third day of the heatwave there is still a temperature reduction of $3.3 \mathrm{~K}$.

As this example shows, PCM-treated wallboard has the potential to convert light buildings, as often found in earthquake areas, intothermally massiveconstructions. In Californian climates with their large diurnal swings, thermally massive residences can be kept comfortable without applying mechanical cooling or evaporative cooling using night-time ventilation to discharge the latent storage of the wall-

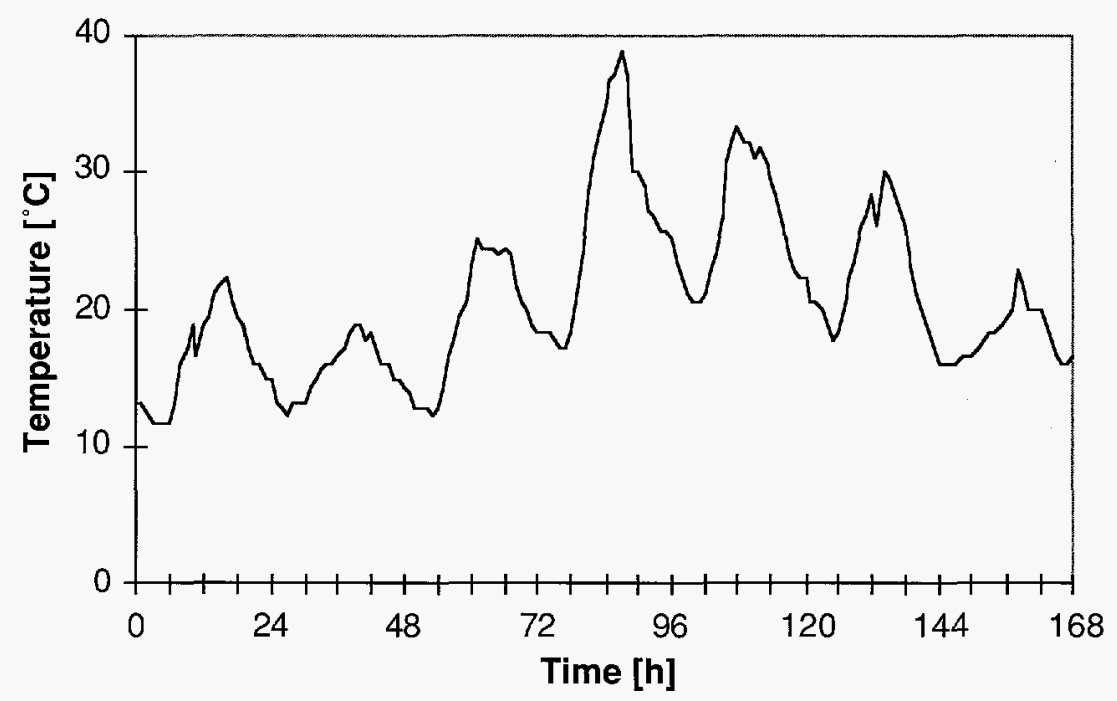

Figure 1. Ambient air temperature profile, June 11-17, San Jose, California.

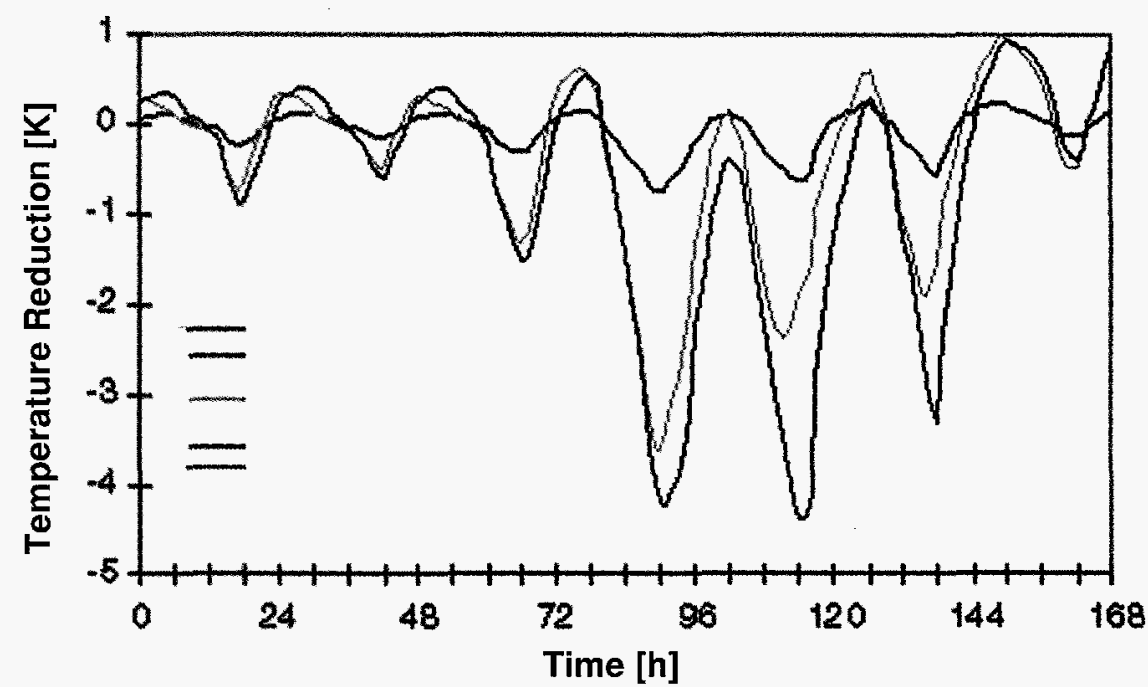

Figure 2. Reduction of operative temperature for double conventional and single and double PCM-treated wallboard when compared with single-conventional wallboard. 


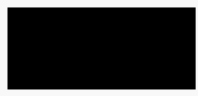

\section{Low-Flow Fume Hood}

H.E. Feustel and R. Simionas

Fume hoods are enclosed work spaces, intended to capture, contain, and exhaust fumes, vapors and particulate matter generated inside the enclosure. In laboratory buildings, the exhaust flows of fume hoods often exceed the fresh air supply requirements for the building's occupants set by ventilation standards. The exhaust air requirement for fume hoods provides a severe energy penalty because all air to be exhausted has to be conditioned before it is supplied to the laboratory space.
In conventional fume hoods, containment of hazards is based on a face velocity high enough to prevent the escape of airborne contaminants from the hood into the room. This face velocity usually is about $100 \mathrm{fpm}(0.5 \mathrm{~m} / \mathrm{s})$, which amounts to approximately $500 \mathrm{cfm}(850$ $\mathrm{m}^{3} / \mathrm{h}$ ) for a three-foot-wide fume hood with an open sash (compared to $36 \mathrm{~m}^{3}$ / $h$ for an occupant).

In order to study the airflow pattern and the airflow requirements for a fume hood, a mockup was built with a dis- placement ventilation outlet which protects the critical perimeter of the open face. By supplying a low-turbulent displacement flow directly at the open face of the hood, we were able to reduce the exhaust flow by about $50 \%$ without decreasing the effectiveness of the hood.

Additional work is needed to optimize the supply/exhaust flow fraction of the hood, design of the displacement ventilation outlet, and the flow patterns within the hood to minimize air exhaust without increasing the risk of spillage.

\section{Indoor Radon Research}

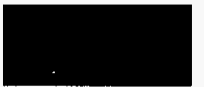

Atmospheric Pressure Variations as a Source of Radon Entry into Buildings

A.L. Robinson, R.G. Sextro, W.J. Riley,
Although advective flow of radonbearing soil gas driven by sustained indoor-outdoor pressure differences is generally recognized as the dominant entry mechanism for radon into most buildings, recent theoretical and experimental studies have shown that atmospheric pressure fluctuations can also draw soilgas into houses. Last year we described experiments which examined the effect of changes in atmospheric pressure on soil-gas entry into an experimental basement structure. We present here results of an expanded investigation which considered the effect of atmospheric pressure fluctuations on radon entry into this structure.

The experimental basement structure was designed and constructed to study the effect of structural and environmental factors on radon and soil-gas entry into houses. The floor slab of the structure rests on a $0.1-m$-thick high-permeability gravel layer. We use two hot-wire anem-ometers mounted in a U-shaped tube to measure the soil-gas flow rate through a hole $3.8 \mathrm{~cm}$ in diameter in the center of the structure's floor. A small volume of gas is continuously sampled from this tube and passed through a lowflow continuous radon monitor to determine the radon entry rate.

Atmospheric pressure fluctuations draw soil-gas into the structure because

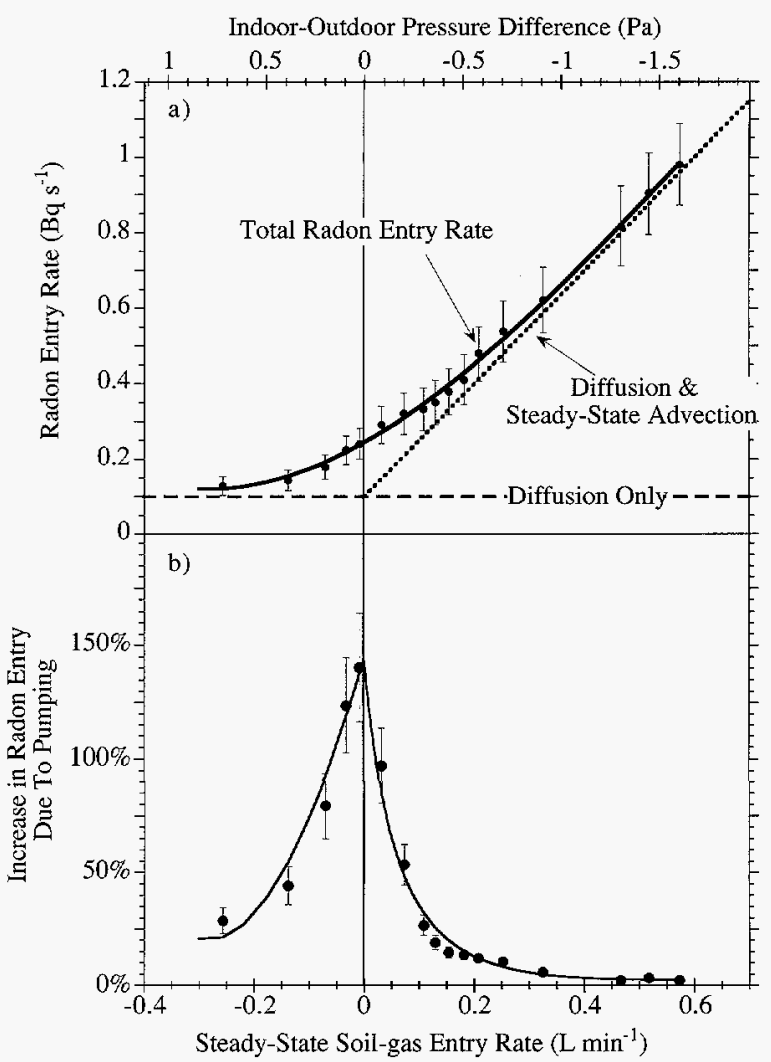

Figure. Enhancement in net radon entry rate into an experimental basement structure due to atmospheric pressure fluctuations. Part (a) shows the radon entry rates from diffusion, steady-state advection and atmospheric pressure fluctuations. Solid line through the measured data is a smooth fit to the data to guide the eye. Entry rates caused by diffusion and steady-state pressure differentials are based on previous experiments. Part (b) shows the increase in radon entry rate attributed to atmospheric pressure pumping compared with the sum of diffusion and steady-state advection. 
of the finite response time of the soil to a change in pressure. This finite response time creates a pressure difference between the interior of the structure and the surrounding soil-gas which, in turn, drives soil-gas entry. Falling atmospheric pressure drives soil-gas entry into the structure; rising atmospheric pressure forces indoor air back into the soil. Although the net flow rate of soil-gas into the structure driven by fluctuations in atmospheric pressure is zero, this flow causes a net radon entry into the building because the radon concentration of the soil-gas is several orders of magnitude larger than that indoors.

The figure summarizes the enhancement in the net radon entry rate into the basement structure due to atmospheric pressure fluctuations. Part (a) illustrates the radon entry contributions from the three entry mechanisms, diffusion, steady-state advection and atmospheric pressure pumping. The data points represent radon entry rate measurements made in these experiments. Estimates of the diffusive and steady-state advective entry rates are based on a series of separate, earlier experiments.

The increase in radon entry caused by atmospheric pressure fluctuations compared with that caused by the combination of diffusion and steady-state advection is shown in part (b). If there is no indoor-outdoor pressure difference, atmospheric pressure fluctuations increase the long-term radon entry rate into the structure by more than $150 \%$. As the structure interior becomes pressurized relative to the atmosphere, the enhancement of the net radon entry rate falls off, approaching the diffusive limit. This occurs because pressurizing the interior of the structure drives indoor air into the soil thereby reducing the volume of radon-laden soil gas drawn into the structure by atmospheric pressure fluctuations. As the structure interior becomes depressurized relative to atmospheric pressure, the enhancement in the net radon entry rate again decreases. This occurs because depressurizing the interior of the structure dramatically increases the advective radon entry rate. In comparison, the relative importance of the entry attributed to atmospheric pressure fluctuations becomes smaller.

These results show that atmospheric pressure fluctuations can increase substantially the net radon entry rate into our experimental structure under conditions when the steady-state entry rate is low. This transient radon entry rate may explain the elevated indoor radon concentrations observed during periods of low steady-state driving conditions.

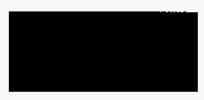

Wind-Induced Ground-Surface Pressures Around Residential Buildings A.J. Gadgil, W.J. Riley, and W.W. Nazaroff

Advective (i.e., pressure-driven) entry of radon-bearing soil gas is the primary mechanism contributing to observed concentrations in most residential buildings with high indoor radon. The pressure differences driving the flow of soil gas into the building are quite small, usually less than five Pascals, compared to the atmospheric pressure of $101 \mathrm{kPa}$. The pressure differences arise from indoor-to-outdoor air temperature (hence density) differences, operation of exhaust fans in bathrooms and kitchens, and the wind flow around the building. In modeling this phenomenon the reference outdoor air pressure on the ground surface has commonly been taken to be the atmospheric pressure at the ground surface. We showed recently that the ground surface pressure induced near a house owing to the interaction of wind with the house can cause very large changes in the predicted radon entry rates into the house, compared to the entry rate calculated in the absence of such wind (see article on this topic in Indoor Environment Program 1994 Annual Report,
LBL-36551). We now report on further research, in which we investigate the wind-induced ground surface pressure field experimentally in a wind tunnel. Then we use these data to determine the adequacy of predicting the ground surface pressure field under the same conditions using a $k-\varepsilon$ model of turbulent air flow.

The experiments were performed in an atmospheric boundary-layer wind tunnel at UC Berkeley's Department of Architecture. The test area of the wind tunnel has a cross section of $1.5 \mathrm{~m}$ high by $2.1 \mathrm{~m}$ wide. A scale of $1: 61$ was used in all the experiments. At this scale the model blocked $0.2 \%$ of the wind-tunnel cross-section. The model house (unscaled footprint of $8.7 \mathrm{~m}$ by $10.4 \mathrm{~m}$, height $3 \mathrm{~m}$, and $6: 12$ pitch roof) could be rotated at any angle to the incident wind by means of a turntable. Pressure transducers were used to measure the distribution of ground surface pressures around the model building and the freestream dynamic and static pressures. Experiments were conducted for two different atmospheric boundary layers corresponding to "countryside" and "suburban" terrain. Separate experiments were conducted with gabled and flat roof models, and data were recorded at eight wind angles for each model and each boundary layer.

A commercially available software package, FLUENT, was used to predict the ground surface pressures around the house with a k-e turbulent model. The modeled physical space around the house, which extended six house dimensions in the horizontal plane and 61 meters in the vertical direction, was discretized into 100,000 control volumes. The computational predictions of ground surface pressure were compared to experimental measurements with respect to their impact on predicted radon entry rates. From this comparison, we determined that the FLUENT model adequately predicts ground surface pressure in this application for simple building shapes. Thus, future parametric studies of wind effects on radon entry could use k-e model predictions in place of the more expensive and time-consuming wind-tunnel studies. 


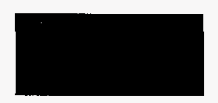

\section{Developing a Methodology for Identifying High-Radon Areas of the United States}

A.V. Nero, P.N. Price, and K.L. Revzan
Researchers at Lawrence Berkeley National Laboratory have estimated previously thatapproximately $90 \%$ of U.S. homes with annual-average radon concentration of greater than $20 \mathrm{pCi} / \mathrm{L}$ are sited in approximately $10 \%$ of the country's area. A method for determining the geographic distribution of indoor concentrations would therefore be extremely useful, since monitoring and control efforts could be concentrated in those areas to find and fix the high-radon homes as rapidly as possible.

The objective of the current research program is to find a way to use available monitoring data in conjunction with data on physical parameters such as soil types and climatology to create a statistical predictive model of local indoor radon concentrations. Such an approach promises results that may compete in accuracy, with those of a massive monitoring program, but at dramatically lower cost and effort.

The simplest way of producing a predictive model for indoor radon concentrations is to use conventional regression techniques to correlate data on indoor radon levels with available explanatory variables. In many cases, these explanatory variables are available only as an area-average not associated with individual houses. For example, in the State Residential Radon Surveys conducted by moststates of theUnited States with assistance from the Environmental Protection Agency, the exact house locations are not available the only location information is the county in which the measurement was made.

Several difficulties arise from using the results of conventional regression models to predict actual county radon concentrations. A major problem is the sparsity of data in many counties. In the State Residential Radon Surveys, many counties had only a handful of measurements, so the actual average radon concentrations for those counties are not known. Because measurements within a county are extremely variable, it takes many measurements to characterizeaccurately a county's average radon concentration.

Another problem is that different sets of indoor radon data are often collected with different sampling protocols (long-term vs. short-term, for example), so the question of how to combine data from different sources cannot be answered easily.

In order to address these problems and others, we use a statistical technique known as Bayesianhierarchicalmodeling. Although the details of this statistical procedure are too involved to describe here, the basic idea is to create a detailed statistical model that relates the observations to the explanatory variables, including all sources of error and variability, and then to estimate all of the model parameters from the data. Previously we used this approach to estimate mean "screening" indoor radon concentrations by county in the state of Minnesota.

Recently we used these techniques to generate conversion equations that allow short-term "screening" radon measurements to be used to predict distributions of long-term living-area concentrations. We have also used these statistical techniques to investigate the distribution of indoor radon concentrations, and the extent to which the distribution can be predicted from geologicand house construction variables in several parts of the country.

For example, we used screening measurements, explanatory variables (including house construction data), and geologic information provided by colleagues from the U.S. Geological Survey to predict screening radon concentration distributions in the mid-Atlantic states. We then used equations to convert these predicted screening distributions to predictions of annual-average living-area concentration distributions. Validation checks indicate that the statistical model performed very well in producing predictions that are both more precise and more accurate than those obtained from other methods. The analy- sis shows that in the mid-Atlantic states, the explanatory variables have as much utility in predicting the geometric mean radon concentration in a county as would having an additional ten to fifteen radon measurements in the county, a substantial increase over the actual number of observations made in most counties.

We mapped the estimated geometric mean of annual average-living-area radon concentrations by county(Figure). This map should be interpreted with caution because the uncertainties vary by county depending on the amount of information available; in practice, some counties with moderate predicted levels are likely to have high (or low) geometric mean radon concentrations. However, the map does correctly indicate important features, such as the high and variable concentrations in eastern and central Pennsylvania, the somewhat elevated radon concentrations along the Appalachians (the diagonal band from the southwest to the north-central part of the map), and the low concentrations in eastern Virginia and western West Virginia.

We are continuing to apply the new statistical techniques to radon data, and are increasing the sophistication of the statistical models to include features such as spatial correlation. The full suite of analyticalmethods is being developed into a package that can be used by researchers to predict and map concentrations of radon (or other environmental pollutants) at county and sub-county scales.

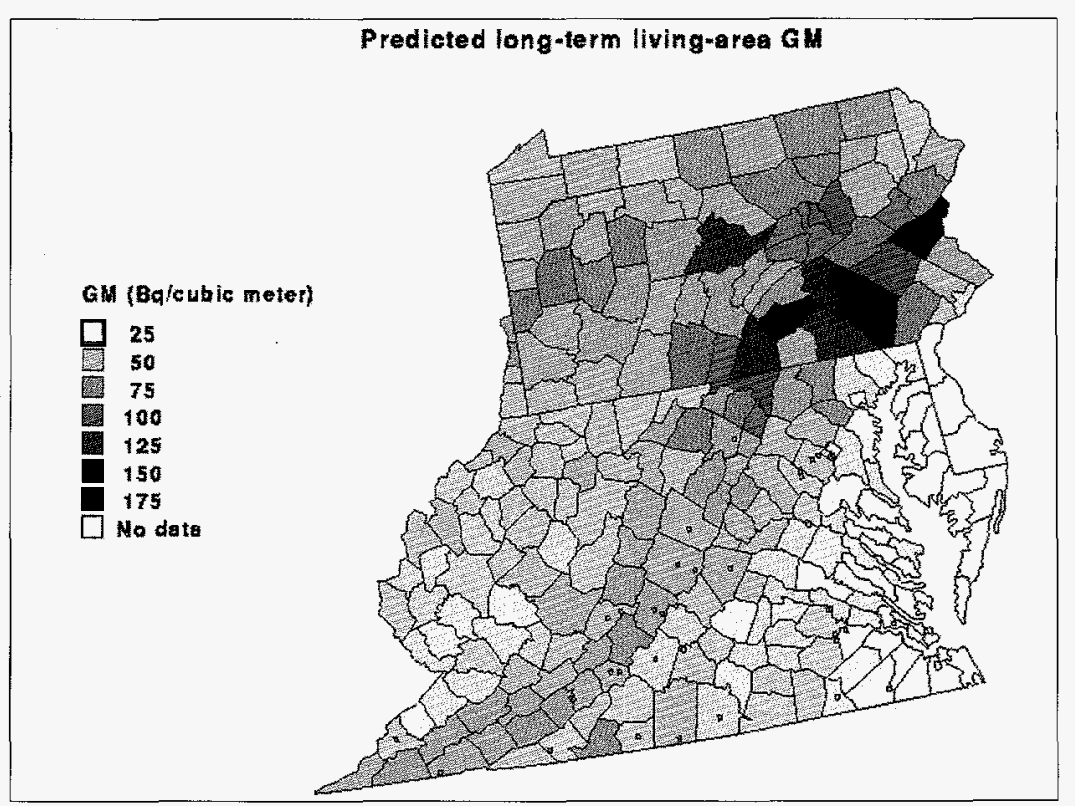

Figure. Map shows estimated geometric mean of annual radon concentrations (by county) for an average living area. 


\section{Characterization of Indoor Pollutants}

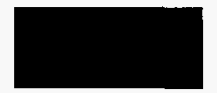

Development of a Carbon Monoxide Passive Sampler

G.W. Traynor, M.G. Apte, and G. Chang
Some 15,000 to 20,000 carbon monoxide poisonings occur every year in the U.S. contributing to hundreds of deaths and thousands of cases of physical or mental damage. Exposures to high concentrations of $\mathrm{CO}$ can damage fetuses and could cause the onset of heart attacks. Residential combustion appliances such as poorly tuned unvented kerosene- and gas-fired space heaters or malfunctioning vented combustion space and water heaters can produce high concentrations of $\mathrm{CO}$. Other causes include the indoor use of charcoal and the indoor operation of internal combustion engines (e.g., operating cars or generators in a garage). Some poisonings can be avoided by better education, whereas others (for example, those caused by malfunctioning vented appliances) can only be detected by an active mitigation program or the widespread installation of CO alarms. Of special concern are the poor and the elderly who often cannot afford routine inspections and maintenance of gas or other combustion appliances.

The dangers of $\mathrm{CO}$ poisoning indicate that there is a critical need for a costeffective CO sampling device for residential and occupational diagnostic studies, indoor exposure studies, and targeted mitigation studies. A CO passive sampler would be the ideal measurement tool for such studies. The goal of our research program is to develop a passive sampler that will require no power, be suitable for deployment through the mail, be stable for several weeks before and after deployment, and have an accuracy and precision within $20 \%$.

Our research group has modified a commercially available disk from Quantum Group Inc., San Diego, California that changes its transmission of near-infrared radiation in the presence of $\mathrm{CO}$. Working closely with the staff at Quantum Group, we tested many new formulations to increase the sensitivity of the disks, reduce the batch-to-batch variations, and reduce the reversibility of the disks. To date, we have established the linearity of the sensors' response to $\mathrm{CO}$; developed and tested a critical non-reversible formulation of the sensor; tested new sensor substrates that are free from impurities; and developed an improved second-generation laboratory prototype (Figure).

The first $\mathrm{CO}$ passive sampler prototype was field-tested during a one-week period at four locations: Bldg. 44 at LBNL, a parking garage toll booth, a residence with a gas range, and an environmental chamber with an unvented gas-fired space heater. The results of the field tests were very promising. All passive sampler values were within 1.1 ppm of the true concentration measured by analyzing air collected with low-flow bag samplers. The field CO concentrations ranged from 1 to $12 \mathrm{ppm}$. Only at the lowest concentration site did the passive sampler and true concentrations differ significantly, which indicates that 1 ppm-week may be close to our limit of detection.

Theimproved second-generation prototype is actually built into a laboratory spectrometer cuvette which facilitates the handling and analysis of the passive sampler. Other improvements include the reduction in size and weight of the passive sampler for deployment as an occupational or personal dosimeter and the removal of all detachable small parts which will allow the sampler's deployment in houses with small children. The new prototype was successfully deployed in a parking garage field test. Future activities include: continuing to adapt this technology for use as a carbon monoxide occupational dosimeter; designing a portable near-infrared analyzer; and increasing the post-deployment shelf life of the passive sampler.

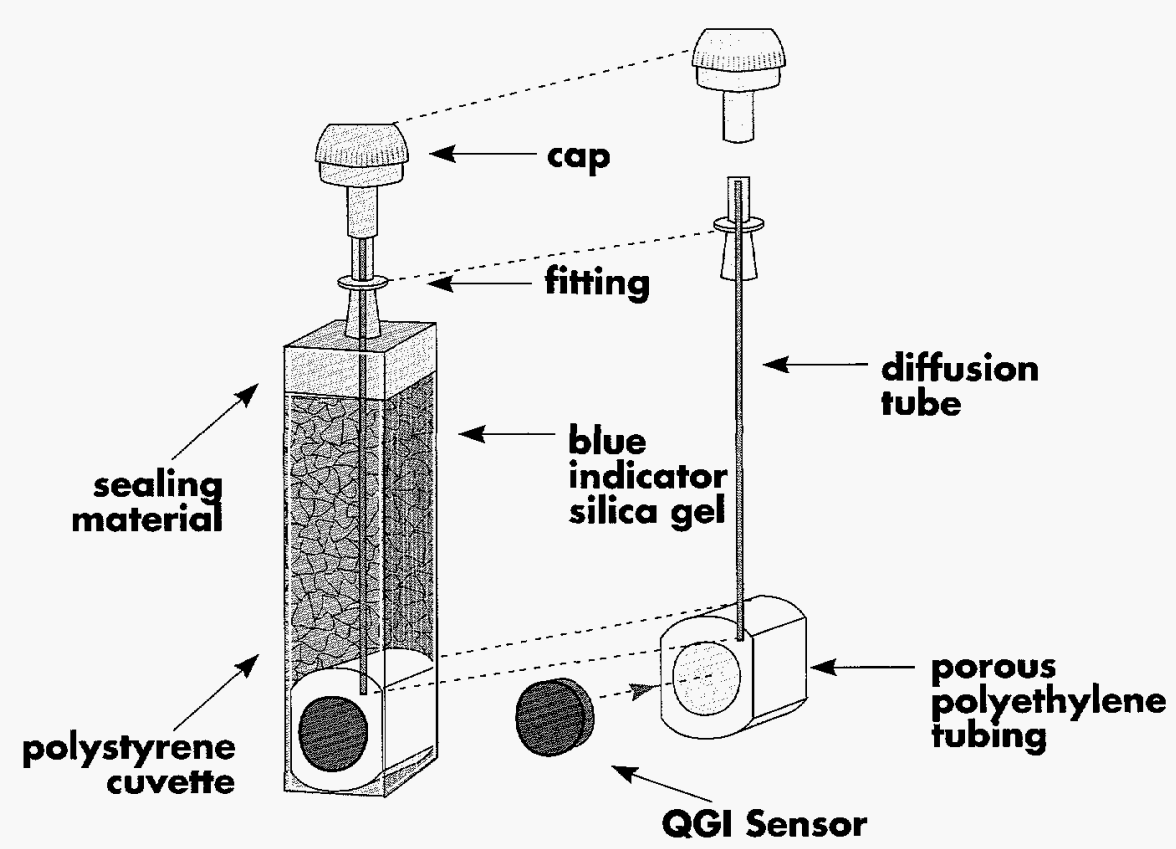

Figure. Schematic diagram shows improved laboratory prototype carbon monoxide passive sampler using a Quantum Group Inc. (QGI) sensor (XBD 5504-01270). 


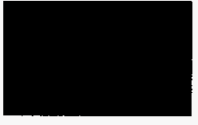

Phase Distributions of Poly

L.A. Gundel and D.A. Lane*
Semivolatile organic pollutants distribute between the gas and particulate phases according to the ambient temperature and their vapor pressures. Human health effects from exposure to such species are phase-dependent since lung deposition patterns differ in the gas and particulate phases. The environmental fates of these species are also phase-dependent because atmospheric reactions and transport and deposition processes differ for the gas and particulate phases.

Most phasedistribution measurements have been made by determining the concentrations of particulate-phase semivolatile organic species from filters that are followed by adsorbents such as polyurethane foam, and macroreticular polymeric resin beads such as Tenax and XAD-4. The material retained by the adsorbents is used to find the gas phase concentrations. Becausesuch sorbent beds follow filters, desorption of semi-volatile compounds from the particles on the filters, or adsorption of gases by the filter materials, i.e., positive particulate-phase artifacts, have led to incorrect measurements of gas- and particulate-phase concentrations.

Recently LBNL developed a novel annular denuder-based Integrated Organic

\footnotetext{
* Atmospheric Environment Service, Environment Canada
}

Vapor/Particle Sampler (IOVPS) to measure gas-and particle-phase distributions of carcinogenic polycyclic aromatic hydrocarbons in environmental tobacco smoke. The IOVPS operates at up to $10 \mathrm{~L} /$ $\mathrm{min}$ for periods from $30 \mathrm{~min}$ to one hour in ETS. Diffusion denuder technology provides a less artifact-encumbered approach for accurate determination of phase distributions of semivolatile species because the gas phase is collected before the particulate phase. An annular denuder is composed of two or more concentric glass tubes through which air is pumped. Large particles are removed from the airstream by a size-selective inlet that is followed by a coated denuder surface that collects and retains gas-phase species that diffuse from the moving airstream. The success of the IOVPS depends on the fact that sufficient ground XAD-4resinadheres tosandblasted glass and is resistant to removal by handling, solvent washing and air sampling. The coated surface does not influence particle transport to a downstream filter. A sorbent or denuder placed after the filter collects any material desorbed from the particles collected on the filter. Concentrations of gas and particulate species are determined from separate extracts of the denuder(s) and filters.

Recent collaborative efforts with the Atmospheric Environment Service of Environment Canada have led to devel- opment and testing of a higher capacity version of the IOVPS that has been used successfully to determine phase distributions of polycyclicaromatic hydrocarbons in ambient air in Berkeley. The denuder surfaces of the gas and particle (GAP) sampler (developed at the Atmospheric Environment Service of Environment Canada) have been modified by coating with XAD-4 resin using techniques developed at LBNL for the IOVPS. The resulting high capacity integrated organic gas and particle sampler (IOGAPS) has been operated in ambient air at $17 \mathrm{~L} / \mathrm{min}$ for a 24-hour period in Berkeley. Simultaneous measurements were made at the same collection rate with a conventional sampler that used a filter followed by two sorbent beds. Gas and particle partition measurements were determined for 13 polycyclic aromatic hydrocarbons ranging from two-ring to six-ring species. The IOGAPS found a higher particle fraction of these compounds than did the conventional sampler, suggesting that the conventional sampler suffered from the expected "blow-off" losses from the particles collected on the filter.

Transfer of LBNL's patent-protected annular denuder technology to the private sector is the subject of a Cooperative Research and Development Agreement between DOE and University Research Glassware of Carrboro, NC.

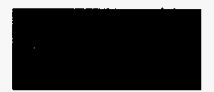

Field Study of Indoor Air Quality at a Site of Subsurface Gasoline Contamination M.L. Fischer, A.J. Bentley, K.A. Dunkin*, A.T. Hodgson, W.W. Nazaroff, R.G. Sextro, and J.M. Daisey
Soil gas transport of volatile organic contaminants into buildings has been documented as a potentially significant source of human exposure to VOCs. The volatile components of gasoline and other petroleum hydrocarbons cause concern because of the large number of storage tanks that are expected to be leaking and previous studies reporting indoor air contamination. Estimating indoor air VOC concentrations caused by subsurface sources providesanimportant inputwhen assigning priorities for remediation ac-

\footnotetext{
* Department of Environmental Science Policy and Management, University of California, Berkeley.
}

tivities. However, purely theoretical estimates of exposure are highly dependent on the sophistication of the models and assumptions used in the estimates. Thus, the results of different studies vary by many orders of magnitude.

In an effort to understand better the factors that affect soil gas contaminant transport into buildings, we conducted a field study at a former gasoline service station building at the Alameda Naval Air Station, California. This station was closed in the late 1980s following leaks of gasoline from a damaged underground storage tank and from feed lines to the dispensing pumps. We began our work by measuring the VOC concentrations in the outdoor and indoor air, soil gas and ground water. Although high concentrations $\left(-30 \mathrm{~g} / \mathrm{m}^{3}\right)$ of several compounds found in gasoline were measured in the soil gas at depths of $0.7 \mathrm{~m}$ below the building, the measured indoor air concentrations in the building were approximately six orders of magnitude lower, a much larger difference than the three orders of magnitude more typically observed. Our study then focused on the physicallimitations to transport, and biological consumption of the VOCs. Measurements included depth profiles of selected VOCs, $\mathrm{CH}_{4}, \mathrm{O}_{2}$, and $\mathrm{CO}_{2}$, the chemical and physical properties of the soil, tracer gas tests of diffusive and advective transport in the soil and of the ventilation characteristics of the building, and a con- 
trolled laboratory test of the rate of biodegradation of selected VOCs in the soil.

The figure shows the soil gas concentration profile of several chemical species in the soil below the building. A sharp gradient in the isopentane (a volatile constituent of gasoline) and methane concentrations between depths of 0.4 and $0.65 \mathrm{~m}$ is apparent in the figure. These results, along with the laboratory tests of biodegradation, suggest that vertical transport of VOCs through the soil is affected by soil characteristics and biological activity, producing the concentration gradients seen (Figure). We combined these results in the context of a simplified box model to estimate the size of theeffects of building ventilation, physical limitations to soil gas transport, and biodegradation. We estimate that dilution of soil gas entering the building via ambient building ventilation reduced the VOC concentration by a factor of $\sim 1,000$, that the physical limitations to transport reduce the soil gas concentrations of all gas species by a factor of $\sim 10$, and that biodegradation further reduces the concentration of these VOCs by another factor of $\sim 100$.

The effects of physical reduction in soil gas transport and microbial degradation of contaminants are likely to affect indoor air concentrations of contaminants to varying degrees at other sites. In par- ticular, although near-surface aerobic biodegradation of aliphatic petroleum hydrocarbons may occur faster than the biodegradation of other compounds in less aerobic environments (particularly halogenated hydrocarbons in the deep sub- surface), similar types of effects may be observed. Our results suggest that detailed estimates of VOC transport into buildings should be made with careful attention to theidentification and separation of physical and biotic effects.

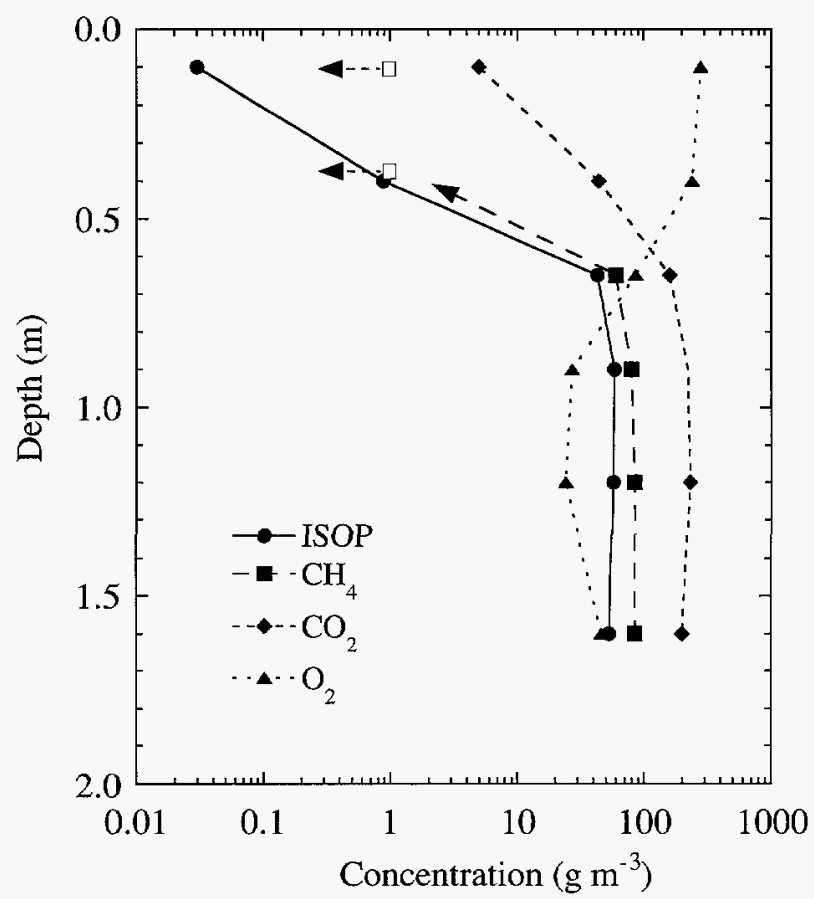

Figure. Concentrations of isopentane (ISOP), methane, carbon dioxide and oxygen in the soil gas at various depths below the building slab. Methane was not detected in the soil gas at depths of 0.1 and $0.4 \mathrm{~m}$; the open squares are plotted at the detection limit.

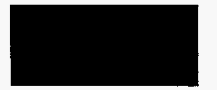

Investigation of the Fate of Nicotine in a Stainless-Steel Chamber M.D. Van Loy, V.C. Lee, L.A. Gundel, R.G. Sextro, W.W. Nazaroff, and J.M. Daisey
To better understand processes which affect the fates of semivolatile organiccompounds in indoor air, several models describing surface interactions of these compounds were developed and tested using data fromexperiments with gas-phasenicotine in a stainless steel chamber. Nicotine is a major constituent of and widely used marker for environmental tobacco smoke. However, the suitability of nicotine as a marker for ETS has been questioned by some researchers because gas-phase nicotine exhibits different decay patterns than many other ETS constituents. Elucidation of the factors affecting nicotine concentrations in indoor environments would facilitate more accurate assessment of ETS exposures. Additionally, these data may be applicable to predictions of indoor concentrations of other SVOCs in indoor air and to estimates of human exposures to these pollutants.
Many SVOCs have associated health effects, ranging from irritation to carcinogenesis or teratogenesis in some cases. Because of their low vapor pressures, these compounds interact strongly with surfaces, readily sorbing on many materials found insidebuildings. Reversibly sorbed compounds may reenter the gas phase by desorbing from surfaces, so occupant exposures to these contaminants may occur for several hours after elimination of the primary source. If the sorbed compounds participate in heterogeneous chemistry on indoor surfaces, the health effects of any potential products with significant vapor pressures must be considered as well. Past studies of organic compound behavior in indoor air have focused on fairly volatile compounds such as toluene and trichloroethylene. Additionally, these studies have inferred the effects of sorption by comparing observed gas phase concentrations with predictions of first-order removal processes based on the chamber or building ventilation rate. Thus, an important component of the mass balance equation for organic compounds in indoor air has been left largely unexplored and SVOCs have hardly been considered at all.

Three experiments were conducted in which nicotine was emitted in a sealed $20-\mathrm{m}^{3}$ stainless steel chamber either by cigarette combustion (smoldering) or by evaporation of pure liquid nicotine. The chamber initially was sealed with the mechanical ventilation system off during and for three hours following nicotine release. It was then ventilated at 3.4 air changes per hour for two hours to flush out the remaining gas-phase nicotine. Finally, the chamber was resealed for another two hours to allow reemission of sorbed nicotine from chamber sur- 
faces. Measurements were taken of nicotine in the gas phase, in the airborne particle phase, and sorbed to chamber surfaces in an effort to close the mass balance for nicotine. However, in each experiment the fate of approximately $85 \%$ of the nicotine mass emitted into the chamber could not be directly determined from the experimental data.

Several models based on possible interactions of nicotine with the chamber were considered as explanations for the experimental results. The nicotine decay processes considered were first-order irreversible deposition; second-order chemical decay; reversible linear sorption on chamber surfaces; reversible nonlinear sorption with a surface-catalyzed reaction; and fully irreversible sorption with limited surface sites. Experimental data and model predictions of gas-phase concentrations and sorbed nicotine mass are shown (Figure) for an experiment in which $33 \mathrm{mg}$ of nicotine was flash evaporated. None of the tested models is fully consistent with the experimental data. Clearly, the interactions of SVOCs with indoor surfaces are very complex and currently available models do not adequately describe the ongoing physical and chemical processes. This topic merits further investigation because information about it is scarce and it could have a significant impact on estimations of human exposures to toxic air contaminants.

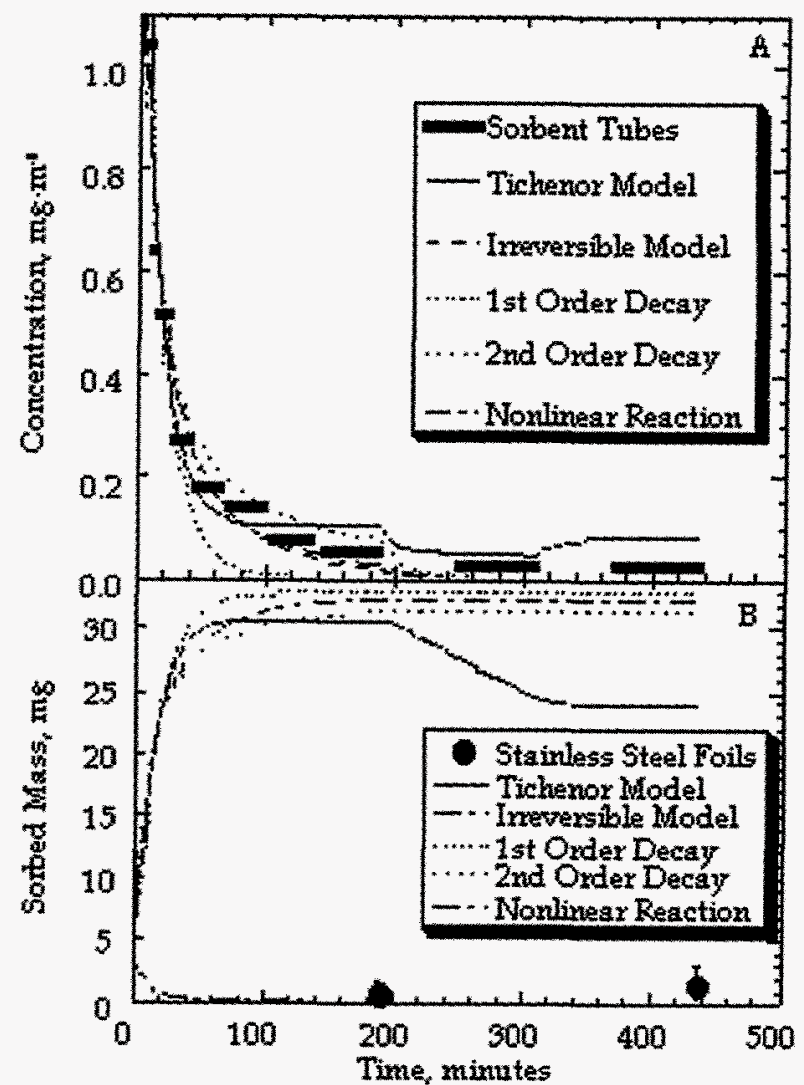

Figure. Experimental data and model predictions for gas-phase concentration and mass of nicotine sorbed or deposited, from an experiment in which $33 \mathrm{mg}$ of liquid nicotine were evaporated in the chamber.

Length of horizontal bars in $(A)$ indicates times and durations for gas-phase sampling with sorbent tubes filled with XAD-4 resin. Solid circles in $(B)$ show estimated sorbed mass on chamber surfaces, based on quantitation of nicotine extracted from several $0.05-$ $m^{2}$ stainless-steel foils placed on interior surfaces of chamber.

\title{
Ventilation and Indoor Air Quality
}
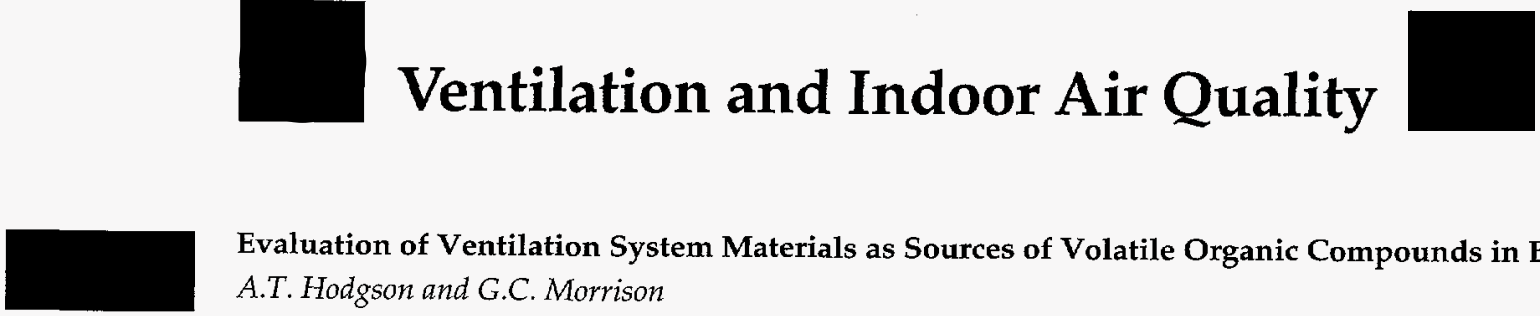

\author{
Evaluation of Ventilation Syst
A.T. Hodgson and G.C. Morrison
}

Studies of office buildings in Europe and in California have found a consistent correlation between the prevalence of some nonspecific health symptoms among office workers and the presence of mechanical ventilation systems, especially those with air conditioning. One possible explanation for these symptoms is that heating ventilating and air conditioning systems are primary sources of pollutants such as volatile organic compounds.

HVAC systems in office buildings contain a variety of materials. Commonly, air ducts are made of sections of sheet metal, sealed to one another with a duct sealant or polymer gasket. Near vibrating machinery such as fans, sections of duct may be connected by flexible joints made of a polymer-coated fabric. To deaden sound and increase thermal efficiency, duct liners are often installed inside the ducts. Building air filters and the fan machinery are other potential VOC sources.

A laboratory study was undertaken to measure the emission rates of VOCs from a variety of materials commonly used in HVAC systems of office buildings.
Samples of representative new duct liners, duct sealing caulks, neoprene gaskets, flexible ducts and joints and building air filters were obtained directly from distributors, from sheet metal fabrication shops or from building construction sites. Samples of used duct liners were collected from several office building HVAC systems that had been in operation for a number of years. The emission rates of VOCs from these materials were measured using small-volume environmental chambers. The samples were placed individually in 10-L stainless-steel cham- 
bers operated at standardized conditions of $23^{\circ} \mathrm{C}, 50 \%$ relative humidity and a $1 \mathrm{~L} /$ min air flow rate. Air samples for the analysis of VOCs and aldehydes were collected periodically from the chambers during a 24-hour period. Some of the materials were exposed subsequently in the chambers to approximately $100 \mathrm{ppb}$ ozone for an additional 24 hours with all other conditions held constant. Air samples for VOCs and aldehydes were also collected periodically during the ozone exposure period. The VOC samples were collected on sorbent tubes and analyzed by thermal desorption gas chromatography/mass spectrometry for total VOCs (TVOCs) and individual compounds. Aldehyde samples were collected on cartridges and analyzed by high-performance liquid chromatography for formaldehyde and acetaldehyde. Emission rates of the analytes in the chamber experiments were calculated using a simple mass-balance model which assumes constant, steady-state conditions.

In addition, in situ measurements of emissions of VOCs from an HVAC system were made in a large, one-year old office and classroom building. Three main air-handling units serve this seven-story structure. These systems contained most of the materials investigated in the laboratory, although not necessarily from the same manufacturers. The air handling unit which served the core of the building was selected for investigation. Air samples for VOCs and aldehydes were collected simultaneously at the air intake at ground level, from the intake duct just before the air handling unit, directly after the supply fan, from a supply vent in a room on the sixth floor, and at the building exhaust. The building had been operating continuously at $100 \%$ outside air (i.e., no recirculation of interior air) for 48 hours prior to the study and also during the collection of samples.

Most of the materials investigated in the laboratory were characterized by low emission rates. For example, new duct liners, which provide the largest surface area of the commonly used HVAC system materials, had TVOC emission rates at 24 hours that were at or near the lower limit of detection of about $300 \mu \mathrm{g} / \mathrm{m}^{2} / \mathrm{h}$. One of these new duct liners had a formaldehyde emission rate of about $80 \mu \mathrm{g} /$ $\mathrm{m}^{2} / \mathrm{h}$, which was the highest value for any of the materials. Several of the used duct liners had higher TVOC emission rates at 24 hours because a few individual compounds were present. New building air filters were also characterized generally by low emission rates of TVOC. Neoprene gasketing and a duct sealer compound had the highest emission rates of TVOC and individual VOCs, but HVAC system contain relatively small amounts of these two materials. Mass-balance modeling predicted none of the selected HVAC system materials to be a significant contributor to VOC concentrations in office buildings relative to typical indoor VOC values for such buildings.

Exposure of the new duct liners to ozone for 24 hours resulted in measurable increases in the emission rates of TVOC. These increases were caused largely by the production of acetone and $\mathrm{C}_{5}-\mathrm{C}_{10}$ straight-chain aldehydes. Organic acid production was not measured. These aldehydes are interesting because they have low odor thresholds. However in all cases, ozone uptake and the production of aldehydes decreased over the 24-h exposure period.

The results from the classroom/office building showed that there was no significant increase in VOC concentrations between the outdoor air at the intake and the sixth floor room supply air. Concentrations of TVOC at these locations were about $100 \mu \mathrm{g} / \mathrm{m}^{3}$ while the concentration of TVOC in the building exhaust air was $230 \mu \mathrm{g} / \mathrm{m}^{3}$. Thus, the in situ building measurements corroborated the results obtained in the laboratory from individual HVAC system materials.

Based on the results of this study, it is unlikely that materials typically used in office building HVAC systems are significant primary sources of VOC contamination. This is because the air flow rates in HVAC systems are high and either the emission rates of VOCs from HVAC system materials are low or only small amounts of higher-emitting materials are used. The study also demonstrated that it is possible to make direct measurements of emission rates of VOCs in building HVAC systems provided that there is no or minimal recirculation of indoor air and that the building is operating at near steady-state conditions. Additional study is needed to determine whether there is any significant sorption of VOCs from air onto major HVAC system materials such as duct liners. If so, these materials might function as secondary sources of contamination under some circumstances. Measuring VOC emissions from HV AC systems in a variety of buildings would also be useful.

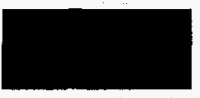

Field Measurements of the Pollutant Control Index

D. Faulkner, W. Fisk, D. Sullivan, and J. Thomas, Jr.

As described in the FY92 and FY93 annual reports, we have proposed a simple new index, the PollutantControl Index, for characterizing the effectiveness of a building's ventilation system in controlling the indoor concentrations of a simulated pollutant. The PCI is effectively a time-average pollutant concentration during the period of occupancy at locations where occupants breathe. The pollutant source is simulated with numerous tracer gas sources (50 to 100) with known emission rates distributed throughout a building uniformly per unit floor area. The PCI is adjusted for any variation in emission rates between buildings. Theindexremains valid when airflow rates vary over time and with any type of ventilation system, such as natural or mechanical. In addition, the PCI can be representative of an extended time period such as a work-week or work-month.

Field studies are underway to evaluate the protocol for measuring the PCI. The primary objective is to determine the minimum required tracer gas source density (sources per unit floor area) necessary for accurate measurements of the PCI. In the field studies, two tracers were spaced at the same density but placed at different locations in the occupied space. In an initial set of experiments with the sources spaced about one per cubicle or roughly every three meters, the two tracers yielded nearly identical PCI values at each sample location (see figure). In a second set of experiments with the sources spaced at half the density or double the distance (every six meters), the two tracers did not give nearly identical values of PCI. Therefore, in this study, the exact location of the sources was not important as long as the sources were uniformly spaced at one per cubicle or every three meters. 
Values for the PCI are normalized so that a value of 100 corresponds to perfectly mixed indoor air and continuous ventilation at the minimum rate specified in the American Society of Heating, Refrigerating and Air-Conditioning Engineers Standard 62-1989, "Ventilation for Acceptable Indoor Air Quality" (seven occupants per $100 \mathrm{~m}^{2}$ supplied with 10 liters per second of outside air). Values for the PCI less than 100 indicate better ventilation than specified in ASHRAE Standard 62-1989. During the first set of three measurement, the average values for PCI ranged from 45 to 58 . During the second set of three measurements, the average value for PCI ranged from 26 to 38. These average PCI values indicate that the ventilation rate in the occupied space or more precisely, the effectiveness in controlling indoor-generated pollutants, was substantially better than specified in the ASHRAE Standard. The PCI values were higher by about a factor of two in the first set of measurements because one of two ventilation systems was inoperative.

The PCI measurements also indicate the spatial variability of ventilation. During individual measurement periods, lo- cal values of PCI ranged from about 80 to $120 \%$ of the average value. The figure illustrates the values of PCI obtained at different indoor locations during one experiment.

Additional field studies are underway in different buildings to determine the tracer gas source density required for accurate measurements of the PCI. We expect that PCI measurements will eventually prove to be more practical and more widely applicable than the conventional tracer gas procedures used to study ventilation in buildings.

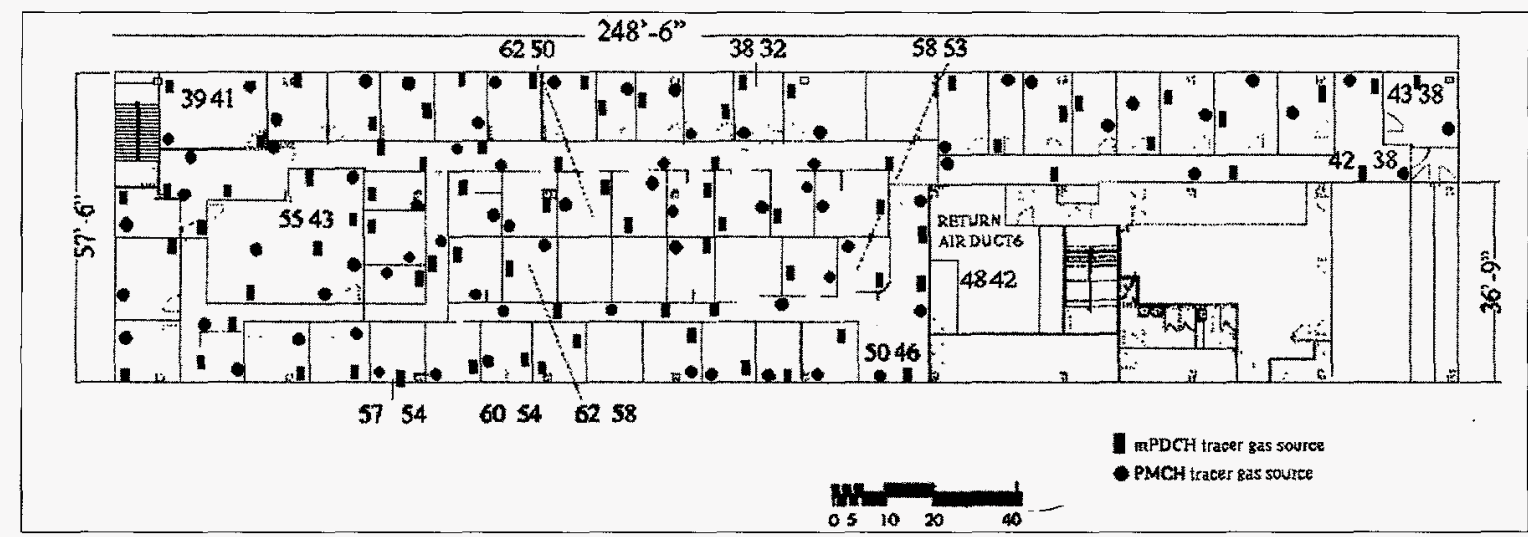

Figure. Floor plan illustrating locations of tracer-gas sources and measured values of Pollutant Control Index for workday period August 16-17, 1995. The left PCI number is based on the mPDCH tracer gas and the right number is based on the PMCH tracer gas. For perfectly mixed indoor air, $\mathrm{PCI}=100$.

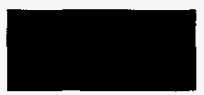

Evaluation of Indoor Air Quality in New Energy-Efficient Houses A.T. Hodgson

The U.S. Department of Energy's Building America Program has the objective of advancing comfort and energy efficiency in new housing through systems engineering approaches. Houses are being constructed in several locations in the United States using these innovative approaches. At completion, the houses are evaluated for their energy performance, including periodic testing of the building envelope for air tightness. Since improved energy efficiency in these houses is often achieved in part by reducing overall ventilation rates, the sources of indoor airborne contamination must also be significantly reduced in order to have acceptable indoor air quality. One of the most important classes of indoor air contaminants with respect to health and comfort effects is volatile organic compounds, which are frequently emitted by new building construction and interior finish materials. Consequently, architects and contractors must carefully select materials used in the construction of energy-efficient houses.

The objective of this study is to quantify the concentrations of VOCs and their source strengths (i.e., the mass of VOCs emitted by materials per unit time) in energy-efficient houses that are part of the Building America Program. The first phase of this study has been completed. The concentrations of total VOCs (TVOC) and individual VOCs including formaldehyde were measured periodically during one year in two similar, new houses from the same project. One house (House A) was built conventionally, while the other (House B) was an energy-efficient structure incorporating design innovations. Ventilation rates were determined concurrently with air sampling so that source strengths of VOCs could be esti- mated using a mass-balance approach.

There were no substantial differences in indoor air quality between the two houses. The TVOC concentrations in House A ranged from 1.7 to $4.4 \mathrm{mg} / \mathrm{m}^{3}$, the highest value coinciding with thelowest ventilation rate of about 0.1 air changes per hour. The TVOC concentrations in House B were 2.4 to $2.8 \mathrm{mg} / \mathrm{m}^{3}$. All of these values were elevated compared to typical residential TVOC concentrations. The dominant VOC in both houses was hexanal, an odorous chemical irritant. The concentrations of acetone, pentanal, tolueneand alpha-pinene were also relatively high in both houses. The concentrations of some of these compounds were consistently above their odor thresholds, and therefore, were likely having an adverse odor impact in the houses.

Generally, it is expected that the source strengths of VOCs emitted by most mate- 
rials used to construct the interiors of houses will decrease with time as the materials age and that substantial decreases in source strengths will be observed during a period of several weeks to a few months. However, the source strengths of many of the compounds detected in the air in these houses did not decline substantially during the one-year period. Three dominant compounds, hexanal, pentanal and alpha-pinene, occurred in approximately the same ratios over time in both houses. For House B, the average combined source strength of these three compounds was estimated to be about $140 \mathrm{mg} / \mathrm{h}$. Assuming that they derived from a continuously emitting source, their total emissions in the course of the year was estimated to be in excess of one kilogram. Therefore, the source itself must have had substantial mass and is likely to have been a major building component.

A large quantity of strand board (OSB) was used in the construction of both houses. A sample of OSB used as subflooring was collected from House B. The measurement of emissions of VOCs from this OSB in a small-scale chamber suggested that this material might have been a significant source of formaldehyde and acetone in the houses. It also suggested that OSB was not the dominant source of pentanal, hexanal and alpha-pinene. Additional investigation is underway to identify the dominant source of these compounds.

Protocols for the measurement of VOC concentrations and source strengths in houses were developed during this first phase of the study and are now being used to investigate indoor air quality for other new houses in the Building America Program. Weanticipate that this approach of combining these field measurements with laboratory chamber studies of materials can identify the significant sources of airborne contamination in residential construction. Architects and contractors can use this information to help guide their selection of materials, ultimately leading to improved indoor air quality in new energy-efficient houses.

\title{
Electronics Reliability and Indoor Air Quality
}

\author{
A. Litrak, A. Gadgil, and W. Fisk
}

Reliability of electronics is a growing concern in the industrial economies that increasingly depend on smaller and faster devices for electronic communication and information processing. Air pollution within buildings is a not widely recognized source of failure of electronic systems.

Airborne particles appear to play an especially significant role in electronic equipment failures. Particles can deposit on circuit boards through a variety of mechanisms including gravitational settling, inertial impaction, diffusional deposition, and deposition caused by electrostatic and thermophoretic forces. An accumulation of particles on the circuit board can result in a leakage of current or arcing between conductive paths. The consequence may be a catastrophic circuit board failure or a parametric failure in which the circuit functions outside of specified tolerances. The deposition of hydroscopic particles, such as nitrate and sulfate salts is especially important. With a sufficient concentration of moisture in the surrounding air, these deposited salts deliquesce and become conductive.

More work is needed to understand better the mechanisms involved in the deposition of aerosol particles on electronic surfaces. For example, we do not have analytical tools to predict the locations where the particles will deposit preferentially on the electronic surfaces and we do not understand the specific impacts of their deposition on the electrical resistance between conductors and circuit reliability. We cannot predict quanti- tatively the deposition rates as a function of factors such as the local electric field strength, air velocities, temperature differences and particle characteristics. An improved understanding of these issues should lead to methods to reduce the failure rates of electronic equipment.

The Indoor Environment Program is initiating research on indoor pollutants and electronic equipment reliability. Our near-term research objectives are to demonstrate unambiguously that deposition of particles causes premature failures of electronic systems and to investigate the process and rates of aerosol deposition on circuit boards.

In the laboratory, we are studying the deposition of hygroscopic fine particles on two different electronic devices: small portable black-and-white television sets and standardized electronic circuits (called "coupons"). Television sets have been chosen to represent electronic devices typically occurring in office buildings, since TV sets have integrated circuits as well as video circuits with high voltages and strong electrical fields typical of computer video display terminals. Each of the standardized electronic circuit coupons consists of a dummy chip with legs spaced $0.35 \mathrm{~mm}$ center-to-center. These legs are connected to conducting surface traces on the circuit board, which lead to an edge connector. Electrical resistance between legs is measured with an electrometer.

Our initial experiments will use both the TV sets and the standardized circuits coupons to get qualitative results about the failure rate of a typical electronic device, and also to relate the failure rate to the deposition rates and inter-trace electrical isolation on the standardized circuit coupons. Subsequent experiments, using only the coupons, will focus on specific details of the deposition process such as the rates and locations of deposition as a function of particle size, electrostatic field strength and particle charge distributions.

Wehavebuilt two small environmental chambers to expose the electronic circuit surfaces (television sets and circuit coupons) to two different indoor environments. In the first chamber, the surfaces are exposed to a high concentration of hygroscopic aerosol particles (fine mode particles of ammonium sulfate). In the second chamber, the surfaces are exposed to the ambient air to simulate aerosol particulate deposition in normal conditions.

We expect to be able to compare the failure rates of TV sets in the two chambers, and to demonstrate that deposition of hygroscopic aerosol particles, in conjunction with high relative humidity, can cause high rates of failure for the TV sets and a dramatic decrease in the inter-trace electrical isolation of the surface-mounted chip on the standardized circuit coupon.

After completing an initial set of experiments in FY 1996, we will initiate the development of a numerical model of the deposition process in early FY 1997. Research based on experiment-model comparisons, model verification and parametric simulations will continue through FY 1997. 


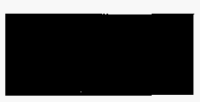

Energy Savings from Demand-Controlled Filtration in Cleanrooms D. Faulkner, W. Fisk, J. Walton*, and J. Bracchini*

Cleanrooms are used extensively in the manufacturing of electronic parts, such as integrated circuits and in the biological and pharmaceutical industries. To maintain extremely low particle concentrations in cleanrooms, for example less than 100 particles per $\mathrm{ft}^{3}$ at $>0.5$ microns size, the air in the room must be filtered. Typically, air in a cleanroom is circulated through high efficiency particulate air filters at a very high rate (e.g., 400 to 600 room air volumes per hour). The high recirculating air flow usually is maintained 24 hours per day every day of the year, despite temporal variations in particle production in the cleanroom. The combined effect of very high air recirculation rate and pressure drop through HEPA filters leads to high electrical energy use per unit floor area for a cleanroom compared to a typical commercial building. For a $1,000 \mathrm{ft}^{2}$ Class 100 cleanroom, the annual cost for electricity to operate the recirculation fans is approximately $\$ 6,000$.
In this study, we evaluated a new procedure, called demand-controlled filtration, for maintaining acceptable particle concentrations in cleanrooms. In DCF, cleanroom particle concentrations are monitored continuously and air recirculation rates are automatically controlled at the minimum value required to maintain acceptable levels of cleanliness in the cleanroom based on real-time measured particle concentrations,.

An experimental evaluation of $\mathrm{DCF}$ was undertaken in a Class 100 cleanroom. An inexpensive $(\$ 2,500)$ optical particle counter was used to measure particle concentrations. Depending on the choice of baselineenergy use, the energy consumption of the recirculating fans was reduced by 60 to $80 \%$. The estimated payback period for a $1,000 \mathrm{ft}^{2}$ Class 100 cleanroom is one to four years. During the study, the particle concentration in the cleanroom was maintained at Class 100 standards $98 \%$ of the time. Industrial cleanroom users that reviewed the study results, stated that the research was useful and should be pursued further. They indicated that DCF is most directly applicable to small research cleanrooms.

The components of DCF technology, computer control systems for heating, ventilation and air conditioning systems, variable frequency drives for fan motors, and particle counters, have been developed, refined and reduced in price within the past decade. The use of computercontrolled systems and variable frequency drives has become a fairly routine practice in buildings. Commercialization of this technology will create jobs in control-system companies and companies that manufacture components of the technology. This technology benefits U.S. industry and research institutions through reduced energy costs resulting in increased competitiveness, and society through the reduced emissions of greenhouse gases to the atmosphere.

*Engineering Division, LBNL

\section{Indoor Air Exposures and Risks}

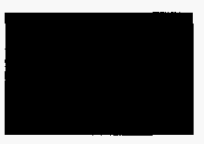
Development of New VOC Exposure Metrics Related to "Sick Building Syndrome"
Symptoms in Office Workers

J. Ten Brinke, J.M. Daisey, A.T. Hodgson, and S. Selvin

There is now a large body of evidence that "sick building syndrome" (SBS) symptoms are widely experienced by office workers in Europe and the United States. SBSis defined by the World Health Organization as a complex of subchronic symptoms that occur during building occupancy and generally decrease when occupants leave the building. SBS is most evident in the extreme cases in which the building occupants experience unusually severe, frequent, or widespread symptoms. In some extreme cases, office workers have had to be evacuated from the building and the building abandoned.

Characteristic "sick building syndrome" symptoms include irritation of the eyes, nose, or throat; headache; fatigue; dry or itchy skin; and difficult breathing or chest tightness.

Surveys of office buildings conducted in the United States and Europe suggest that $20 \%$ or more of the occupants in buildings without known problems frequently experience SBS symptoms. The costs of SBS symptoms in U.S. office workers has been estimated to be billions of dollars annually from health care costs, lost work days and lost productivity. More severe cases of SBS often result in costly litigation.

It has often been suggested that the SBS problem iscaused by the reduction of building ventilation to conserve energy, and the term "tight building syndrome" is sometimes used to refer to SBS. Concerns about SBS have sometimes been a barrier to use of more energy-efficient ventilation such as variable air volume systems. Determin- ing the causes of SBS is essential to optimizing building ventilation rates, energy use and human health and comfort.

\section{Possible Causes of SBS}

Research indicates that SBS is multifactorial in origin, i.e., that the cause is a combination of psychosocial, individual and environmental factors (e.g., inadequate ventilation, poor air quality). In studies of SBS in Europe and the United States, a number of factors have been identified consistently and convincingly as being related to SBS sealed, air-conditioned buildings; carpets; high density of workers per $\mathrm{ft}^{2}$ of floor space; and an outside ventilation supply of approximately less than 10 $\mathrm{L} / \mathrm{s}$-person. Exposures to volatile organic compounds from both indoor and outdoor sources are also suspected to be a factor. 
Exposures to VOCs and SBS Symptoms

There are several reasons for suspecting that VOCs are a factor in SBS symptoms. Industrial workers exposed to many of the same VOCs as those measured in buildings experience the same kinds of symptoms observed for SBS.

However, industrial workers usually are exposed to only one or two VOCs at very high concentrations. In office buildings, workers typically are exposed to perhaps a hundred or more VOCs, each at a concentration that is about $1 / 1000$ th of the concentration known to cause such symptoms. For this reason, it has been suggested that the total concentration of all VOCs is what is important. Concentrations of total volatile organic compounds in office buildings are typically about $0.5 \mathrm{mg} / \mathrm{m}^{3}$, although in some buildings TVOC reaches levels of 2 to $10 \mathrm{mg} /$ $\mathrm{m}^{3}$. In these buildings there is some evidence of higher SBS symptom rates, but SBS symptoms are also reported for buildings with low TVOC concentrations.

\section{Exposure Metrics for Environmental Agents}

We have hypothesized that there is an association between reported SBS symptoms and exposures to VOCs at low concentrations but that better exposure metrics than TVOC are needed to demonstrate this connection. The term "exposure metric" refers to the measurement of the potential or actual agent or combination of agents causing adverse health effects. Thus, a metric consists of what is measured, how it is measured, and how multiple agents are combined mathematically. Regarding exposures to airborne pollutants, a common metric used for VOCs has been TVOC. However, the mixture of VOCs varies from building to building, and different VOCs have different biological potencies. Thus, one VOC might be 100 times more irritating than another at the same concentration. In developing exposure metrics for VOCs, we hypothesized that the variability of the potencies of VOCs must be taken into account in the metric. In addition, some groups of VOCs co-vary in concentration because they originate from the same source or source type, so we also considered how to reduce the number of different VOCs to a smaller set of factors that could be related to different sources.

\section{Approach}

We focused on the SBS symptoms of irritancy and first developed an inte- grated, relative irritancy scale for the VOCs. This scale was based on mouse bioassay data because there is so little irritancy data for controlled human exposures to VOCs. The mouse bioassay determines the $\mathrm{RD}_{50}$, the concentration that causes a $50 \%$ reduction in breathing rate in exposed mice. The bioassay has been used to test many VOCs and the results are correlated highly with human responses. Missing data for some VOCs was estimated from correlations between the $\mathrm{RD}_{50}$ values of the bioassay and vapor pressures by chemical class. Since we were interested in relative irritancy, the $R_{50}$ of each VOC of interest was divided by the $\mathrm{RD}_{50}$ for toluene. The relative irritancy of the most common indoor VOCs is presented (Table 1, below). There is a factor of more than 100 difference between the most and least irritating VOC in this table.

We developed and tested several different exposure metrics for the mixtures of VOCs commonly found in indoor air using data collected in the California Healthy Buildings Study (summarized in Table 2). The metrics included TVOC, the total irritancy-weighted concentration of the measured VOCs, total odor threshold-weighted concentration of VOCs, and several metrics derived using principal component analysis of the measured VOCs.

Principal component analysis converts multiple, highly correlated variables to a reduced number of linearized sums of the individual VOCs, or principal components. Correlated VOCs tend to group on a single $\mathrm{PC}$ because certain groups of VOCs increase or decrease (i.e., group) in concentration together because they have a common source type. Some VOCs originate from more than a single source type and are then associated with more than one PC. Thus, this methodology effectively apportions the VOC among its sources. We also suspect that the PCs may trace the presence of other, higher molecular-weight compounds which are probably present but are not sampled and analyzed with the usual VOC methods.

Multivariate logistic regression models were used to investigate the relationship between reported SBS symptoms and each of the exposure metrics. The results are reported as the odds ratio (OR), which represents the odds of experiencing a symptom (versus the odds of not experiencing a symptom) in relation to the VOC exposure metric. The model of symptom prediction was 'adjusted' for various risk and protective factors: demographic characteristics (gender, age, race, education, job); building characteristics and activities that might affect exposures (ventilation type, new paint nearby, time spent at photocopier); environmental characteristics (temperature and relative humidity); individual sensitivity (asthma, hay fever, smoking history, knowledge of the status of a building as "sick"). Each symptom model was tested with and without the exposure metric and results compared to determine if the exposure metric provided improved prediction of the symptom.

\section{Results}

Most of the tested metrics, including TVOC, were not effective in predicting the SBS irritancy symptoms. The Irri-

Table 1. Relative Irritancy of Common Indoor VOCs

\begin{tabular}{|lclc|}
\hline Compound & $\begin{array}{c}\text { Relative } \\
\text { Irritancy }\end{array}$ & \multicolumn{1}{c}{ Compound } & $\begin{array}{c}\text { Relative } \\
\text { Irritancy }\end{array}$ \\
\hline Styrene & 7.9 & 3-\& 4-Ethyltoluene & 2.9 \\
Ethylacetate & 7.6 & Ethylbenzene & 1.7 \\
n-Butylacetate & 6.2 & 2-Butoxyethanol & 1.6 \\
1,2,3-Trimethylbenzene & 4.1 & Toluene & $1.0^{*}$ \\
n-Hexanal & 3.9 & Benzene & 0.46 \\
n-Pentanal & 3.9 & x-Propanol & 040 \\
1,2,4-Trimethylbenzene & 3.6 & n-Heptane & 0.26 \\
m- \& p-Xylene & 3.4 & n-Octane & 0.25 \\
1,3,5-Trimethylbenzene & 3.2 & Ethanol & 0.17 \\
2-Ethyltoluene & 3.2 & 2-Propanone & 0.09 \\
o-Xylene & 3.1 & n-Nonane & 0.07 \\
\hline
\end{tabular}

*Reference compound. 
tancy/PC exposure metric (consisting of four principal components or vectors), however, was effective and statistically significant at the $95 \%$ confidence level in the prediction of several SBS symptoms, including skin irritation.

The individual PCs of the Irritancy/

PC exposure metric were then examined in more detail. Two PCs, the carpet/ building materials and the water-based paints and cleaning products PCs, were found to be more useful in symptom prediction; i.e., the sources represented by the first and second PCs were not

Table 2. Overview of the 1990 California Healthy Buildings Study

\section{Buildings:}

- 12 office buildings in the San Francisco Bay area (all nonsmoking):

three naturally ventilated with openable windows

three mechanically ventilated, no air conditioning, openable windows six air conditioned with sealed windows ${ }^{*}$

*One air-conditioned building was a classic problem building with a history of occupant health complaints and unsuccessful health investigations

\section{Measurements:}

- Self-reported SBS symptoms, demographic data from 517 of 880 completed occupant questionnaires

- Environmental measurements taken in 26 spaces in the 12 buildings (data from 22 spaces used):

Temperature

Relative humidity

Average $\mathrm{CO}_{2}$ (40-hour workweek)

TVOC (eight-hour workday)

39 individual VOCs (eight-hour workday)

Total viable fungi and bacteria (two samples collected during a severalminute period in one workday) irritating as measured by their ability to be useful in symptom prediction. The Irritancy/PC exposure metric was reduced to include only the third and fourth PCs. Further, the fourth PC, identified as emissions from water-based paints and cleaning products (containing 2butoxyethanol), accounted for most of the predictive power of the metric and was almost as effective as the full fourPC exposure metric.

The figure presents the adjusted odds ratios for each of the symptoms using just this single PC. For the eye irritation symptom, for example, the odds ratio (adjusted for the other factors) was 1.7 (95\% C.I.: 1.1 to 2.7 ). Therefore, it is the increase in VOC exposure that results in a one-unit change in the PC that will increase the odds of observing skin irritation symptoms from unity $(\mathrm{OR}=1.0)$ to almost twofold (OR $=1.7$ ). We also investigated use of the concentration of 2butoxyethanol, the single most important VOC in this PC, as an exposure metric but found that it was not useful alone. This suggests that multiple sources for some of the VOCs must be taken into account in the exposure metric, i.e., only the fractions of 2-butoxyethanol and associated VOCs emitted from water-based paints and cleaning products are impor-

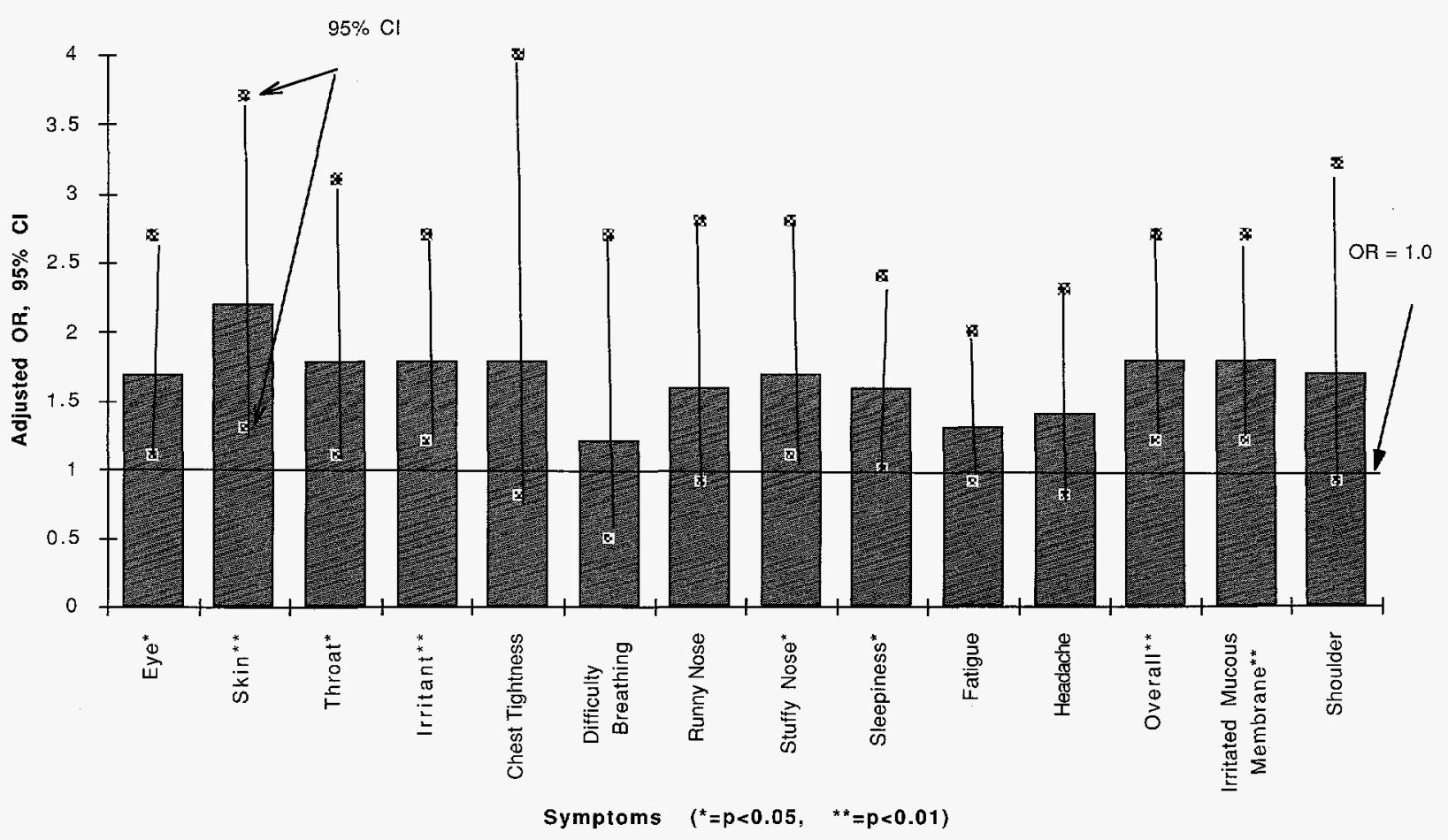

Figure. Odds ratios (adjusted for the other factors) of experiencing a symptom using the PC exposure metric for water-based paints and cleaning products. Odds ratios above one indicate that this PC exposure metric is associated with the specific symptom. 
tant determinants of the irritant symptoms.

Water-based paints contain glycol ethers such as 2-butoxyethanol. Painters, who have much higher exposures, experience eye, nose and throat irritation and headaches from exposures to emissions from water-based paints and also absorb 2-butoxyethanol through the skin. Thus, the relationship observed here between the "water-based paints and cleaning products" PC exposure metric and the skin irritation symptoms in office workers seems reasonable. Many cleaning products used in buildings also contain 2-butoxyethanol.

\section{Implications}

This study demonstrated that emissions from water-based paints and from cleaning products could account for some of the SBS symptoms observed in office workers in the California Healthy Buildings Study. However, results are from a single study and require further investigation and confirmation in other sets of buildings. If confirmed, it should be quite possible to minimize these SBS symptoms by increasing the outdoor air ventilation rate during and for at least a few weeks after painting in occupied office buildings. The ventilation systems should be operated at higher daytime flows over- night to prevent buildup of concentrations of VOCs. Less use of cleaning products with gylcol ethers might help reduce the SBS symptoms as well.

The new methodology developed here to obtain an exposure metric for a complex mixture of VOCs has linked low-level VOC exposures to SBS symptoms for the first time. We believe that this methodology will be useful in determining some of the causes of SBS. Effective control of the agents that cause SBS will allow us to use more energyefficient ventilation without compromising the health and comfort of building occupants.

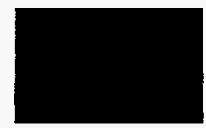

Associations of Measured Temperatures with "Sick Building Syndrome" Symptoms in the California Healthy Building Study

M. Apte, W. Fisk, M. Mendell, D. Faulkner, M. Nematollahi, and C. Peto
Episodes of "sick building synd rome," in which unusually high prevalences of various symptoms of irritation and discomfort in office buildings cannot be explained readily by a recognized disease or environmental exposure, have become an important public health and building energy management issue over the last decade. Typical symptoms of SBS include irritation of the mucosa of the eyes, nose, or throat, headache, fatigue, dry or itchy skin, and chest tightness or difficulty breathing. These symptoms are building-related because they tend to clear up when the affected individuals are away from the building.

The California Healthy Building Study, conducted within twelve public office buildings with 29 study spaces, investigated risk factors for building-related sick-building health symptoms. A questionnaire completed by 880 participants provided demographic information, worker perceptions and symptom data. Indoor and outdoor pollutant concentrations, temperature and humidity were measured during a one-week period. The measured indoor temperatures in the study ranged from $20^{\circ} \mathrm{C}$ to $29^{\circ} \mathrm{C}$. One-week average indoor relative humidity was moderate throughout, ranging from $41 \%$ to $58 \%$. An hypothesis suggested by a review of the literature and tested using the CHBS data is that exposure to non-optimal indoor temperature is associated with an increase in mucosal irritation.

A risk variable was constructed that reflects thermal exposure to temperatures above $20^{\circ} \mathrm{C}$ (units: ${ }^{\circ} \mathrm{C}$-weeks above $20^{\circ} \mathrm{C}$ ). The magnitude of this variable increases as the weekly thermal exposures increase. Multiple logistic regression models containing this main risk variable and covariables to adjust for building, demographic and psychosocial parameters were developed to test the hypothesis. Increased thermal exposure to temperatures above $20^{\circ} \mathrm{C}$, using a binary split of the thermal exposure data at $4.5^{\circ} \mathrm{C}$-week, was found to be associated with a reduced prevalence of irritation to throat, runny nose, and stuffy nose (all symptoms: odds ratio $=0.6$ per ${ }^{\circ} \mathrm{C}$-week, $\mathrm{p}$ $<0.05)$. Questionnaire data on satisfaction with the overall physical environment was observed to be an important covariable in the regression models; exploratory analyses using these data as a variable were conducted. When environmental satisfaction was controlled for in the above models, the association between thermal exposure and the prevalence of these irritation symptoms became stronger (all symptoms: $\mathrm{OR}=0.5, \mathrm{p}=0.01$ ). These exploratory analyses suggest that adjustment for overall indoor environmental dissatisfaction may increase the ability to detect true associations between symptoms and environmental parameters.

The finding that the prevalence of these symptoms decreases with increasing thermal exposure is consistent with certain similar research found in the literature; however, it contradicts other published work, mostly conducted in very cold climatic zones, which indicate that increased temperatures are associated with an increase in the prevalence of symptoms. The difference in the observed effects of temperature in these studies might be due to a fundamental difference in the indoor climates of the buildings studied. The relative humidity in the CHBS buildings was moderate, whereas it has been reported to be very low in buildings studied in cold climates. 


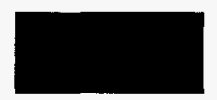

Healthy-Building Intervention Studies

W. Fisk, M. Mendell*, M. Nematollahi, D. Faulkner, D. Sullivan, and J. Thomas, Jr.
Symptoms of sick building syndrome (SBS) are nonspecific health effects associated with occupancy in a building. SBS symptoms include irritation of eyes, nose, throat, or skin, headache, fatigue, chest tightness and difficult breathing. A substantial percentage of office workers report that they experience these symptoms at work and indicate that their symptoms improve when they leave the building. Symptom prevalences vary greatly among buildings. Building-related factors that have been associated with increased prevalences of SBS symptoms in multiple studies include sealed air-conditioned buildings, lower outside air ventilation rates, air temperature, and presence of carpets. Recent research efforts have also found that indoor concentrations of volatile organic compounds, carbon dioxide, endotoxin (from gram negative bacteria), and Beta-1,3-glucan (from fungi) have been associated with increases in SBS symptoms.

The Indoor Environment Program is collaborating with theIndustrywideStudies Branch of the National Institute for Occupational Safety and Health on a program of Healthy Buildings Intervention Studies. The primary research objectives are to test practical methods of reducing SBShealth symptoms among office workers and to gain new, more definitive information on the causal exposures for these health symptoms.

During FY 1995, we completed designs and preparations for intervention studies. In these intervention studies, symptom prevalences or intensities are compared within subjects before and after interventions that change the indoor environment in a manner hypothesized to reduce health symptoms. To the degree possible, all conditions suspected to influence symptoms are held constant except for the condition changed in the intervention. In comparison to cross-sectional studies of multiple buildings, intervention studies provide more unambiguous information on the causes of SBS symptoms. In cross-sectional studies, the prevalences of symptoms in different populations of workers (e.g., workers in many different buildings) is compared, but many building characteristics, indoor

\footnotetext{
*National Institute for Occupational Safety and Health
}

environmental conditions, and demographic and job characteristics often vary between the populations.

Based on a review of literature on the suspected causes of SBS symptoms, the following promising interventions were identified: (1) decreasing concentrations of airborne submicron particles; (2) increasing outside air ventilation rates; (3) improved cleaning of indoorsurfaces (e.g., floors); (4) small changes in air temperature; and (5) reducing concentrations of airborne volatile organic compounds using air cleaners.

Equipment and procedures were selected for two interventions. Upgrading the filters of air-handling systems was determined to be the most practical method of decreasing concentrations of airborne submicron particles. In collaboration with the research department of a major air filter manufacturer, we identified a suitable filter with a $95 \%$ efficiency for $0.3 \mu \mathrm{m}$ particles and an acceptable air flow resistance. Methods to remove pollutants from indoor surfaces such as floors were selected after consultations with a number of research and industry experts. Wet methods of surface cleaning were rejected because they leave a damp surface that may stimulate growth of microorganisms. Chemical-based methods of surface cleaning were rejected because of the potential for residual chemicals to increase symptoms. We selected a technique of dry vacuuming using a vacuum cleaner with a high air flow rate and high-efficiency filtration. A special vacuum cleaner was fabricated for this application.

A new health symptom questionnaire that collects information on the intensity of symptoms during the current day was designed and pilot-tested. Previously available symptom questionnaires have asked subjects to report the prevalence of their work-related symptoms last year, last month, or last week. Errors may result from the subjects' inability to accurately recall their past symptom prevalences.

Several detailed intervention protocols were developed. All protocols involve the simultaneous collection of symptom data from an experimental group (subject to the intervention) and a control group (not subject to an intervention). When the interventions are reversible, the intervention will be cycled on and off approximately weekly with repeated collection of symptom data. The protocols use crossover design, i.e., the experimental and control groups are exchanged between intervention cycles. To reduce the potential that occupants' expectations may influence reported symptoms, interventions will be performed blindly or placebo interventions will be utilized in the control group.

Criteria were established for selection of buildings. These criteria include a sealed air-conditioned building design and the existence of at least two populations (experimental and control groups) of at least 100 workers in regions of the building that are physically isolated. The prevalence of SBS symptoms among the workers must be equal to or above the average prevalence from a large set of buildings studied previously by NIOSH.

Instrumentation was selected and purchased for multi-point real-time measurements of air temperature, humidity, carbon dioxide concentrations, and particle concentrations as a function of particle size. Through consultations and subcontracts with outside experts in the field of microbiology, endotoxin and ergosterol measurements were added to the measurement protocol.

Managers of a large number of federal, state, and county buildings were contacted in a search for appropriate study buildings. A small fraction of office buildings meet our scientific criteria and only a subset of the scientifically acceptable buildings are willing to grant access for a study. One otherwise ideal building was rejected after symptom screening because it had very low symptom prevalences. We are currently seeking access to another suitable building.

In FY 1996, we expect to complete at least one intervention study and to make considerable progress on the data reduction and analyses. The highest priority interventions will be to decrease concentrations of airborne submicron particles, to increase outside air ventilation rates, and to improve the cleaning of indoor surfaces. 


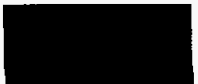

Statistical Tools for Physiologically Based Population Pharmacokinetic Modeling

F. Bois and K. Revzan

Among the tasks of chemical risk assessment is the quantification of the internal dose delivered to target tissues after exposure. At this stage, three levels of extrapolation may be required: interspecies, interroute, and high-to-low dose extrapolations. Physiologically based pharmacokinetic models have been used for more than 10 years to perform simultaneously all of these extrapolations. These models can be used to integrate cumulative human exposure via air, water, soil and food, since it is possible for them to describe concurrent absorption routes. However, there are some scientific issues that must be addressed if PBPK models are to be used with confidence in risk assessment. We are currently working to address two of these: (1) the need to establish sound statistical validation techniques for PBPK models, and (2) the need to develop population toxicokinetic modeling that can be merged smoothly in the framework of Bayesianstatisticsfor use in decision analy- sis and risk management.

One key issue is the current lack of a method for rigorous statistical validation of PBPK models. For example, to our knowledge, the predictions made by such models have never been presented with meaningful confidence levels. Consequently, it is impossible to decide whether the fits are acceptable, the models reasonable, and what confidence to have in the result of extrapolation. Confidence intervals that build only on the basis of a priori information fail to include information brought by pharmacokinetic data and lead to overestimates of uncertainty. In past research, we used partial maximum likelihood optimization or set membership criteria to address these problems. Weare now developing rigorous methods necessary to bring this important area of health risk assessment to the level of statistical quality and reliability required from any scientific activity. These methods will address model parametrization, optimal experimental designs, and linkage with input time series.

Another current research need in risk assessment concerns human variability and its impact. We lack methods to measure the human variability which affect the results of toxicokinetic data. We have begun work to demonstrate that embedding PBPK models in the statistical context of population pharmacokinetics is feasible and provides a rigorous way to describe and account for inter- and intraindividual variability factors. In this, we are facing a new extrapolation problem: how should we extrapolate variability estimates obtained from data on small numbers of subjects to large numbers of individuals (i.e., from small tolarge populations). This question is largely linked to statistical sampling and modeling. In a PBPK model, the parameter variability of observations in small numbers of subjects can be replaced (extrapolated) by that known for larger populations. 


\section{References}

Carrié FR, Modera MP. "Reducing the Permeability of Residential Duct Systems." In: Proceedings of the 16th Annual AIVC Conference ,Palm Springs, CA, September 19-22, 1995; 2: 552-559.

Diamond RC, Feustel HE, Dickerhoff DJ. "Energy and Ventilation Research in High-rise Apartments: The Chelsea Public Housing Study." In: Proceedings of the 16 th AIVC Annual Conference, Palm Springs, CA, September 19-22, 1995; 369-378.

Diamond RC. An overview of the Multifamily Sector. Home Energy November $1995 ; 22$ (6)

Drescher AC. Computed Tomography and Optical Remote Sensing: Development for the Study of Indoor Air Pollutant Transport and Dispersion. Ph.D. Dissertation, University of California Berkeley, 1995. Also published as Lawrence Berkeley National Laboratory Report No. LBL37330 .

Faulkner D. Fisk WJ, Sullivan DP. Indoor airflow and pollutant removal in a room with floor-based task ventilation: Results of additional experiments. Building and Environment 1995; 30 (3): 323 332. Also published as Lawrence Berkeley National Laboratory Report No. LBL-36131.

Fischer M, Bentley A, Bunkin K, Hodgson A, Nazaroff $W$, Sextro R, Daisey J. Factors Affecting Indoor Air Concentrations of Volatile Organic Compounds at a Site of Subsurface Gasoline Contamination. 1995. Lawrence Berkeley National Laboratory Report No. LBL-37768.

Fisk WJ, Prill RJ, Wooley J, Bonnefous YC, Gadgil AJ, Riley WJ. New methods of energy efficient radon mitigation. Health Physics 1995; 68 (5): 689-698. Also published as Lawrence Berkeley National Laboratory Report No. LBL36519.

Friedmann $R$, De Buen $O$, Sathaye J, Gadgil A, Saucedo R, Rodriquez G. Assessing the residential lighting effi- ciency opportunities in Guadalajara and Monterey, Mexico. Energy 1995; 20 (2): 151-159.

Garbesi K, Sextro R, Robinson A, Wooley J, Owens J, Nazaroff W. Scale Dependence of Soil Permeability to Air: Measurement Method and Field Investigation. Submitted to Water Resources Research (1995). Published as Lawrence Berkeley National Laboratory Report No. LBL-35369.

Hodgson AT, Daisey JM, Alevantis LE, Mahanama KRR, Ten Brinke J. Use of volatile tracers to determine the contribution of environmental tobacco smoke to concentrations of volatile organic compounds in smoking environments. Submitted to Environment International (1995). LBL-37376.

Hodgson AT. A review and a limited comparison of methods for measuring total organic compounds in indoor air. Indoor Air (in press, 1995). Also published as Lawrence Berkeley National Laboratory No. LBL-32904.

Jump D, Modera MP. "Impacts of Attic Duct Retrofits in Sacramento Houses." Proceedings of ACEEE Summer Study, Pacific Grove, CA, August 1994. Also published as Lawrence Berkeley National Laboratory Report No. LBL35375.

Lane D, Gundel L. Gas and particle sampling of airborne polycyclic aromatic compounds. Polycyclic Aromatic Compounds (in press, 1995). Also published as Lawrence Berkeley National Laboratory Report No. LBL-37984.

Lin T-F. Transport and Sorption of Volatile Organic Compounds and Water Vapor in Porous Media. Ph.D. Dissertation, University of California Berkeley, 1995. Also published as Lawrence Berkeley National Laboratory Report No. LBL37477.

Mahanama KRR, Hodgson AT.An Improved Impregnated-filter Method for Measuring Low-Level Concentrations of Tolu- ene Diisocyanates in Air. Lawrence Berkeley National Laboratory Report No. LBL-36641, 1995.

Mahanama KRR, Daisey JM. Volatile Nnitrosamines in environmental tobacco smoke: Sampling, analysis, emission factors and indoor air exposures. Submitted to Environmental Scienceand Technology (1995). Lawrence Berkeley National Laboratory Report No. LBL37302.

Modera MP, Jump DA. Field Measurements of the Interaction between Heat Pumps and Duct Systems in Residential Buildings. In: Proceedings of ASME International Solar Energy Conference, March, 1995. Lawrence Berkeley National Laboratory Report No. LBL36047.

Modera MP, TreidlerEB. Improved Modeling of HVAC System/Envelope Interactions in Residential Buildings. In: Proceedings of ASME International Solar Energy Conference, March, 1995. Lawrence Berkeley National Laboratory Report No. LBL-36048.

Price PN. The regression effect as a cause of the nonlinear relationship between short- and long-term radon concentration measurements. Health Physics 1995; 69 (1): 111-114. Also published as Lawrence Berkeley National Laboratory Report No. LBL-35819.

Revzan KL, Price PN, Nero AV. Bayesian Analysis of the Relationship Between Indoor Radon Concentrations and Predictive Variables in UIS. Houses. Lawrence Berkeley National Laboratory Report No. LBL-38194, 1995.

Riley WJ, Gadgil AJ, Fisk WJ. Regional and national estimates of the potential for energy use, energy costs, and $\mathrm{CO}_{2}$ emissions associated with radon mitigation by sub-slab depressurization. Energy and Buildings (in press, 1995). Also published as Lawrence Berkeley National Laboratory Report No. LBL36368. 
RileyWJ, Gadgil AJ, NazaroffWW.Windinduced ground pressures around a single-family house. Journal of Wind Engineering and Industrial Aerodynamics (in press, 1995).

Robinson AL, Sextro RG. Direct measurements of soil-gas entry into an experimental basement driven by atmospheric pressure fluctuations. Geophysical Research Letters 1995; 22 (14): 1929-1932. Also published as Lawrence
Berkeley National Laboratory Report No. LBL-36743.

Schaeffer VH, Bhooshan BB, Chen S-B, Sonenthal $\mathrm{J}$, Hodgson AT. Characterization of volatile organic chemical emissions for carpet cushions. Submitted to Journal of Air \& Waste Management Association, 1995.

Ten Brinke J. Development of New VOC ExposureMetrics and their Relationship to
"Sick Building Syndrome" Symptoms. Ph.D. Dissertation, University of California Berkeley, 1995. Also published as Lawrence Berkeley National Laboratory Report No. LBL-37652.

Wampler DA, Miller-Leiden S, Nazaroff WW, Litvak A, Mahanama KRR, Nematollahi A, Gadgil AJ. Effectiveness of smokeless ashtrays. Journal of Air and Waste Management Association 1995; 45: 494-500.

\section{Sponsors}

Support from the following sources was provided through the U.S. Department of Energy under Contract No. DE-AC03-76SF00098:

- U.S. Department of Energy:

Assistant Secretary for Energy Efficiency and Renewable Energy:

Office of Building Technologies

Building Systems and Materials Division

Building Equipment Division

Assistant Secretary for Environment, Safety and Health, Office of Environmental Analysis

Director, Office of Energy Research:

Office of Health and Environmental Research

Energy Research Laboratory Technology Transfer Program

- National Institute of Environmental and Health Sciences (NIEHS), National Institutes of Health through the University of California at Berkeley

- National Heart, Lung and Blood Institute, National Institutes of Health

- U.S. Environmental Protection Agency

- U.S. Food and Drug Administration

- U.S. Consumer Product Safety Commission

- California Institute for Energy Efficiency (CIEE), a research unit of the University of California

(Publication of research results does not imply CIEE endorsement or agreement with these findings, nor that of any CIEE sponsor.)

- Cigarette and Tobacco Surtax Fund of the State of California, through the Tobacco-Related Disease Research Program of the University of California

- Electric Power Research Institute, Palo Alto, California

- California Air Resources Board

- PEW Charitable Trusts

- Battelle Pacific Northwest Laboratories

- National Institutes of Health through the University of California at San Francisco and Thomas Jefferson University 